\title{
Functional and Oxidative Quality Characterization of Spray-Dried Omega-3-Enriched Milk Powder
}

\author{
Muhammad Ali, ${ }^{1}$ Muhammad Imran $\left(D,{ }^{1}\right.$ Muhammad Kamran Khan, ${ }^{1}$ \\ Muhammad Haseeb Ahmad, ${ }^{1}$ and Niaz Muhammad (iD ${ }^{2}$ \\ ${ }^{1}$ Department of Food Science, Faculty of Life Sciences, Government College University, Faisalabad, Punjab, Pakistan \\ ${ }^{2}$ National Agriculture Education College, Kabul, Afghanistan \\ Correspondence should be addressed to Muhammad Imran; imran@gcuf.edu.pk and Niaz Muhammad; niaz.dotani@naec.af
}

Received 16 December 2020; Revised 19 March 2021; Accepted 19 May 2021; Published 28 May 2021

Academic Editor: Fabio Napolitano

Copyright (c) 2021 Muhammad Ali et al. This is an open access article distributed under the Creative Commons Attribution License, which permits unrestricted use, distribution, and reproduction in any medium, provided the original work is properly cited.

In the present study, fish oil (FO) and wall material were supplemented to milk to produce spray-dried powder (SDP). Furthermore, the mandate of the study was to enlighten the effect of spray-drying (SD) operating conditions on functional and oxidative quality of produced SDP samples. Purposefully, the cow milk was supplemented with $3 \%$ FO as omega-enriched source of eicosapentaenoic acid (EPA) and docosahexaenoic acid (DHA) for development of milk and FO blends (MFOBs). The lecithin was used as an emulsifier and maltodextrin was supplemented as the wall material (WM) in the MFOBs. Initially, the FO, milk fat (MF), and MFOB samples were characterized for EPA, DHA, and peroxide value (PV) before the SD. The SD of MFOB samples was carried out to produce SDP samples by using a mini spray dryer. Central composite design (CCD) with face-centered rotation was used to optimize SD independent conditions such as inlet air temperature (IAT), pump speed (PS), maltodextrin percentage (MD), and needle speed (NS) in the ranges of $160-200^{\circ} \mathrm{C}, 3-9 \mathrm{~mL} / \mathrm{min}, 10-30 \%$, and $5-9 \mathrm{~s}$, respectively. The encapsulation efficiency (EE) ranged between 89.30 and $81.57 \%$. The EPA and DHA retentions were in the ranges of $2.19-1.87 \mathrm{~g} / 100 \mathrm{~g}$ and $3.20-2.75 \mathrm{~g} / 100 \mathrm{~g}$, respectively. The highest results for responses were observed on the following conditions: IAT was $160^{\circ} \mathrm{C}$, PS was $9 \mathrm{~mL} / \mathrm{min}$, MD was $30 \%$, and NS was $9 \mathrm{~s}$, respectively; the minimum values of response factors were obtained on the following conditions: IAT was $200^{\circ} \mathrm{C}$, PS was $3 \mathrm{~mL} / \mathrm{min}, \mathrm{MD}$ was $10 \%$, and NS was $5 \mathrm{~s}$, respectively. The percent losses of EPA and DHA were noted in the range of $2-18 \%$. The IAT was observed as main factor for FA reduction in SDP samples. The SDP samples were stable, and low rate of peroxide values was noted. Overall, spray drying can be potentially used to incorporate the essential fatty acids in milk to produce stable SDP for food applications.

\section{Introduction}

Omega-3 ( $\omega-3)$ fatty acids (FAs) are a significant member of biologically active ingredients belonging to a group of polyunsaturated fatty acids (PUFAs). These have double bonds, where the first double bond is always located at the $3^{\text {rd }}$ carbon atom from the methyl group [1]. FAs like $\omega-3$ PUFAs, especially eicosapentaenoic acid (EPA) and docosahexaenoic acid (DHA), show numerous beneficial positive impacts in boosting the human health [2]. The available previous literature supports the applications of PUFAs to regulate the chronic diseases [3]. DHA is the key constituent to impart significant contributions in development of fetal brain, neurons, sharpness of vision in infants, metabolisms of lipids, and cognitive support. DHA in combination with EPA provides the best results for preventing atherosclerosis, Alzheimer's, rheumatoid arthritis, dementia, and other diseases [4]. Recently published studies have emphasized the importance of utilization of very-long-chain (LC) $\omega$-3 FAs as they play a key role in sharpening learning abilities at childhood and their behavior [5] and also decreased the burden of psychiatric sickness in young age adults [6]. The daily recommended consumption of EPA and DHA ranged from $250 \mathrm{mg}$ to $1000 \mathrm{mg}$ for normal adults and preferably 
higher intake requirements are suggested for both pregnant and lactating females [7]. Generally, the daily consumption of $\omega-3$ FAs in developing countries is very much low or below the recommended intake range $[8,9]$.

The sources of long-chain $\omega-3$ FAs are very limited including marine-fisheries depending upon access and affordability [10]. Worldwide dietary intakes of $\omega-3$ FAs are reported as only $20 \%$ of world's population obtained $250 \mathrm{mg} /$ day of seafood's $\omega-3$ PUFAs [11]. According to "World Health Organization" (WHO) and "Food and Agriculture Organization" (FAO), the fish consumption per serving supplies almost 200-500 mg of EPA and DHA [12]. Other factors that can affect the intake of EPA and DHA are availability, time, and composition of food [13]. So, time is needed to raise the awareness regarding beneficial impacts of EPA and DHA supply among the discerning consumers [4]. Extracted fish oil (FO) has been considered as one of the best sources for the EPA and DHA and can be supplemented into food products [14-16]. One known matrix/carrier medium for provision of $\omega$-3 FAs in human biological system is milk. Milk fat (MF) is uniformly present in micelles which can effectively enhance the surface areas to carry out the bioactive components $[17,18]$. Milk is regularly consumed as food in the diet of infants, children, teenager, pregnant women, adults, and the elderly [19]. Milk and milk-based dairy products are consumed on a daily basis and they can contribute as an excellent way of $\omega-3$ FAs provision in the forms of functional milk, powders, and dairy products [20]. The consumption of EPA- and DHA-enriched food can ultimately reduce the burden of cardiovascular diseases (CVD) and mortality rate [21].

Omega FAs as EPA and DHA have very high susceptibility to autocatalytic lipid oxidation due to presence of free radicals specifically when molecular oxygen is active [22]. Protection of $\omega$-3 PUFAs using spray drying (SD) technique has showed significant results to reduce the oxidative deterioration of these FAs and this technique allows food handlers and technologists to apply these FAs in several food systems [1]. SD is a common practice being applied in the food processing industries and more specifically in the dairy industry to produce stable milk powder. SD also helps to minimize water content to lowest level and reduces oxidation and this process and mechanism give numerous advantages and options for product development [23]. Milk is highly perishable food and application of SD extends its shelf life. Milk powders are mostly used in the food industry because of their nutritional, physical, and functional properties [24]. Noteworthy, SD has economic importance at industrial scale to develop spray dried whey powder, instant coffee, and soups [25-27]. In this regard, projective techniques have been seen as a fast way to assess information about new products and are mainly used for answering the questions regarding new products [28]. Moreover, SD has an advantage to produce products with quality and safety [29]. However, the concept of producing the spray dried powder (SDP) enriched with EPA and DHA is an alternative route for supplementing these important essential FAs in human diet $[19,30]$. SDP may have better storage ability compared to conventional milk fortified with omega FAs. The SD technique may help to maintain the availability of these bioactive omega FAs throughout the year for all age groups and also supports the economic loss by reducing different processing steps from packaging to delivery $[24,31-34]$. The main mandate of the present study was to develop the SDP using optimized SD operating conditions and evaluate the quality of SDP for encapsulation efficiency, omega FAs loss, and oxidative stability.

\section{Materials and Methods}

2.1. Procurement of the Raw Material. The substrate material (milk) was collected from commercial farm. The collected milk samples (MS) were kept at $4^{\circ} \mathrm{C}$. Meanwhile, the fish meal (Catla catla) was purchased from local fish market. Lecithin and maltodextrin (MD) were purchased from chemical supplier (Punjab, Pakistan) which were utilized as emulsifier and wall material (WM) for SD process, respectively. Analytical grade reagents and standards were purchased from Merck (Merck KGaA, Darmstadt, Germany) and Sigma-Aldrich (Tokyo, Japan).

2.2. Milk Fat (MF) Extraction. MF was drawn by following the method detailed by Feng at al. [35] with some modifications. $20 \mathrm{~mL}$ MS was placed within a $50 \mathrm{~mL}$ conical plastic tube and the tube was placed in machine and centrifugation was done at $12,000 \mathrm{rpm}$ for $30 \mathrm{~min}$ at $4^{\circ} \mathrm{C}$. An aliquot of $1.0 \mathrm{~g}$ weight from the formed fat-cake layer was taken to $1.5 \mathrm{~mL}$ micro tube and further it was left at $20-25^{\circ} \mathrm{C}$ for almost $30 \mathrm{~min}$ till the melting point followed by centrifugation by micro centrifugal machine, where rpm was set at 13000 and time was $20 \mathrm{~min}$. Separation of MS into 3 different layers was completed where top most was lipid, middle one was mix of protein/fat/other water insoluble solids, and last layer was water.

2.3. Fatty Acids (FAs) Analysis of MF. The extracted lipid was $40 \mathrm{mg}$ and it was trans-esterified following the procedure of transmethylation [36]. First, $40 \mathrm{mg}$ of sample (oil) was taken and $2 \mathrm{~mL}$ of hexane was then added. Further, $40 \mathrm{~mL}$ of methyl-acetate was added, and this mixture was vortexed. After this, the methylation process was done by adding $40 \mathrm{~mL}$ mixture prepared as $1.75 \mathrm{~mL}$ methanol $+0.4 \mathrm{~mL}$ of $5.4 \mathrm{~mol} / \mathrm{L}$ sodium methylate. Again, the mixture was vortexed and left for $10 \mathrm{~min}$ to complete the reaction. Then, there was addition of termination reagent $60 \mathrm{~mL}$ volume prepared as $1 \mathrm{~g}$ oxalic acid and $30 \mathrm{~mL}$ diethyl ether. The centrifugation was performed at $2400 \mathrm{rpm}$ for $5 \mathrm{~min}$. The temperature was $5^{\circ} \mathrm{C}$. The process produced the prominent layer of hexane. This aliquot of hexane layer was taken and stored at $-20^{\circ} \mathrm{C}$. Fatty acid methyl esters were quantified using a Gas Chromatograph fitted with a capillary column ( $30 \mathrm{~m} L \times 0.25 \mathrm{~mm} \mathrm{ID} \times 0.25 \mu \mathrm{m}$ film thickness). Conditions were set as injector temperature of $230^{\circ} \mathrm{C}$, column-oven temperature of $180^{\circ} \mathrm{C}$ to $210^{\circ} \mathrm{C}$, detector temperature of $250^{\circ} \mathrm{C}$, detector used FID (Flame Ionization Detector), carrier gas used oxygen free nitrogen, and flow rate was $1 \mathrm{~mL} / \mathrm{min}$. The volume of fatty acid oil was $0.1-0.2 \mu \mathrm{L}$. 
2.4. Peroxide Value of MF. Extracted MF was subjected to analysis of peroxide value (PV) following the method of Fang et al. [37]. In a $250 \mathrm{~mL}$ flask, $0.2 \mathrm{~g}$ of extracted oil was weighed and addition of $30 \mathrm{~mL}$ acetic acid ( $3: 2$ solutions) and $0.5 \mathrm{~mL}$ potassium iodide solution was done. After stirring for about 1 minute, $30 \mathrm{~mL}$ distilled water was added to the mixture. At that point, an aliquot of $0.5 \mathrm{~mL}$ starch indicator (1\%) was also added to the mixture, and the resultant solution was titrated against $0.001 \mathrm{~N}$ sodium thiosulfate solution until diminishing the purple color. The calculation of peroxide value was performed as follows: $\mathrm{PV}=(\mathrm{S}-\mathrm{B}) \times \mathrm{N} \times 1000 / \mathrm{W}$, where $S$ is the volume of $\mathrm{Na}_{2} \mathrm{~S}_{2} \mathrm{O}_{3}$ added to the sample; $B$ is the volume of $\mathrm{Na}_{2} \mathrm{~S}_{2} \mathrm{O}_{3}$ of the blank; $N$ is normality of the solution of $\mathrm{Na}_{2} \mathrm{~S}_{2} \mathrm{O}_{3}$, while $W$ is the weight of the sample (g) and PV was expressed as active $\mathrm{O}_{2}$ $\mathrm{mEq}$ (milliequivalent) per $\mathrm{kg}$ of sample.

2.5. Fish Oil (FO) Extraction. The oil extraction from fish meal was done in departmental innovative lab and extracted FO was counted for use as a source of EPA and DHA for supplementation in milk. The unprocessed fish meal samples were weighed by electronic scales (model Kern 440-35N) for each treatment and solvent extraction procedure was adopted for extraction of oil from fish meal [38]. The fish meal and solvent (hexane) ratio was set as $1: 10(w: v)$. For each treatment, the $100 \mathrm{~g}$ of fish meal was weighed in continuous shaker and $1000 \mathrm{~mL}$ of solvent was mixed to extract the lipids. The process was carried out at $30^{\circ} \mathrm{C}$ for 2 hours. After that, the solvent was removed at $50^{\circ} \mathrm{C}$ in a labscale rotary evaporator.

2.6. Fish Oil Purification. The purification of extracted FO was carried out using a series of processes that included different steps such as degumming, neutralization, bleaching, and deodorization [39]. For degumming, the sample of extracted fish oil $(100 \mathrm{~g})$ was placed in $500 \mathrm{~mL}$ beaker. The sample was heated at $70^{\circ} \mathrm{C}$ for exactly $1 \mathrm{~min}$ in the oven. Then, the aqueous citric acid solution of known amount ( $3 \mathrm{~mL}$ of $3 \%$ concentration) was added to the beaker containing heated fish oil. The mixture was gently shaken at $70^{\circ} \mathrm{C}$ for $1 \mathrm{~min}$. The fish oil was then cooled to $25^{\circ} \mathrm{C}$ and centrifugation process was carried out at $2500 \times \mathrm{g}$ for $10 \mathrm{~min}$ to remove the undesirable impurities. The degummed fish oil was neutralized using the sodium hydroxide. For each treatment, the sodium hydroxide $(12.6 \mathrm{~g}$ of $9.5 \% \mathrm{NaOH}$ solution) was added to $100 \mathrm{~g}$ of degummed fish oil. The mixture was gently heated at $65^{\circ} \mathrm{C}$ for consecutive $30 \mathrm{~min}$ with constant stirring using a magnetic stirrer bar. The neutralized fish oil samples were then cooled to $25^{\circ} \mathrm{C}$ and were kept undisturbed for 6 hours. After that, the centrifugation process at $2500 \times \mathrm{g}$ was carried out for $10 \mathrm{~min}$. This process supported to decant the oil from the precipitated soap. Demineralized water $(50 \mathrm{~mL})$ was mixed to each centrifuged sample to wash out any soap residues. This process of demineralized water addition and washing was repeated three times. At the end of neutralization process, the impurities and water contents were removed in the form of separating layer by the application of centrifugation at
$2500 \times \mathrm{g}$ for $10 \mathrm{~min}$. The bleaching of each neutralized oil sample $(100 \mathrm{~mL})$ was performed with $1 \mathrm{~g}$ of acid activated earth clay. The operating conditions were set at $100^{\circ} \mathrm{C}$ for exactly 20 min with constant stirring using a magnetic stirrer bar. The acid activated earth clay and absorbed impurities were removed from bleached fish oil samples using filtration process. This process was completed immediately to avoid chemicals and color of fish oil samples. Finally, the bleached fish oil samples were deodorized with the purpose of removing the free fatty acids, bad odors, and oxidation products.

2.7. FO Analysis. FAs analysis and $\mathrm{PV}$ of $\mathrm{FO}$ was done according to the detailed procedures described in previous sections of FAs and PV analysis of MF.

2.8. Milk and Fish Oil Blend (MFOB) Formation. The FO was added to milk with known volumes for development of milk and FO blends (MFOBs). Each MFOB contained $1000 \mathrm{~mL}$ milk and $30 \mathrm{~mL}$ FO. Further, the WM was added at specific known concentrations $[40,41]$. The MD as WM and lecithin (3\%) as the emulsifier were dissolved in milk under continuous magnetic stirring and were kept for cooling at room temperature. The milk was used as the base material for all formulations to make the emulsions. In order to utilize milk proteins as an encapsulating material, the MFOBs were homogenized with a homogenizer at $25000 \mathrm{rpm}$ for $5 \mathrm{~min}$. After that, the samples were allowed to stabilize at room temperature for $60 \mathrm{~min}$.

2.9. MFOBs Analysis. MFOB samples were characterized for FAs and PV according to the detailed methods described in previous sections of FAs and PV analysis of MF.

2.10. Spray Drying (SD). The SD of MFOB and WM was carried out to produce SDP by using mini spray dryer (TPS15 Lab Spray Dryer, China). The schematic diagram of the lab-scale spray dryer is presented in Figure 1. The evaluation index was based on the performance of ME and the conservation of PUFAs [42]. SD independent variables such as the inlet air temperature (IAT, ${ }^{\circ} \mathrm{C}$ ), pump speed (PS, mL/ $\mathrm{min})$, maltodextrin percentage (MD, \%), and needle speed (NS, s) were optimized using the central composite design (CCD) with face centered rotation as described in Table 1. The SDP samples were collected in collection chamber connected to cyclone separator by locking nut and were directed to collection bottle attached with spray dried chamber. The SDP samples were further analyzed for functional and oxidative quality parameters.

\subsection{Encapsulation Efficiency (EE), Fatty Acids, and Peroxide} Value (PV). Encapsulation efficiency (EE) was determined according to the method detailed by Santhanam et al. [41]. The surface oil content of SDP samples was determined by adding $50 \mathrm{~mL}$-hexane and $5 \mathrm{~g}$ of powder in a volumetric flask and was stirred for $10 \mathrm{~min}$. The powder and solvent 


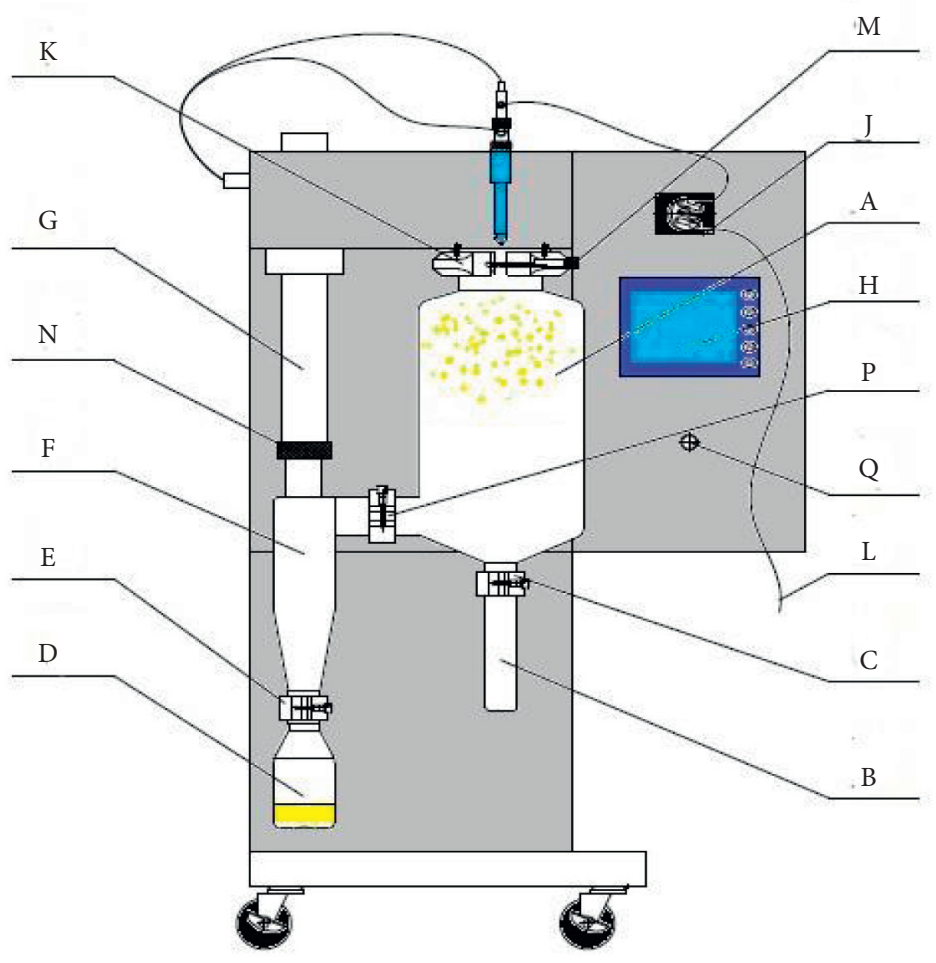

\begin{tabular}{|c|l|c|l|}
\hline M & Locking nut & K & Large hoop \\
\hline J & Peristatic pump & G & Hot air exhausting pipe \\
\hline A & Drying chamber & N & Locking nut \\
\hline H & Touchscreen & F & Cyclone separator \\
\hline P & $3^{\text {rd }}$ hoop & E & $1^{\text {st }}$ hoop \\
\hline Q & Power button & D & Collection chamber \\
\hline L & Feeding tube & B & Collection bottle \\
\hline C & $2^{\text {nd }}$ hoop & & \\
\hline
\end{tabular}

FIgURE 1: The schematic diagram of the lab-scale spray dryer (TPS-15).

TABLE 1: Coded and actual levels of independent variables for optimization of response factors as determined by central composite design (CCD).

\begin{tabular}{lcccc}
\hline \multirow{2}{*}{ Independent variables } & \multirow{2}{*}{ Units } & \multicolumn{3}{c}{ Coded levels } \\
& & -1 & 0 & +1 \\
\hline Inlet air temperature (IAT) & ${ }^{\circ} \mathrm{C}$ & 160 & 180 & 200 \\
Pump speed (PS) & $\mathrm{mL} / \mathrm{min}$ & 3 & 6 & 9 \\
Maltodextrin (MD) & $\%$ & 10 & 20 & 30 \\
Needle speed (NS) & $\mathrm{s}$ & 5 & 7 & 9 \\
\hline
\end{tabular}

were separated using filter paper (Whatman No. 1). The SDP residues left on filter paper were further washed with hexane (solvent) of known volume of $20 \mathrm{~mL}$. The solvent was evaporated and dried off using a rotary evaporator. The total oil of SDP was extracted by Soxhlet extraction technique with hexane. Accurately weighed $5 \mathrm{~g}$ powder was extracted by placing in thimble using $180 \mathrm{~mL}$ volume of hexane for total time of $8 \mathrm{~h}$ to make full extraction of oil. The encapsulation efficiency was assessed using the following formula:

$$
\mathrm{EE} \%=\left(\frac{\mathrm{TO}-\mathrm{SO}}{\mathrm{TO}}\right) \times 100,
$$

where TO is the total oil extracted and SO is the surface oil collected.

Fatty acids and PV of oil samples extracted from SDP were observed as documented in above sections.

2.12. Statistical Analysis. CCD design with face centered rotation was used which was elaborated by quadratic equation for each response parameter. Each treatment of SDP was statistically analyzed for its significant values using software package (MATLAB) as described by Montgomery 
[43]. Optimized run was performed in triplicate and the average mean values were reported with standard deviation. Moreover, the sample analysis was done, and the significant variation was determined among means at a probability level of $5 \%$.

\section{Results and Discussion}

3.1. Characterization of Samples before Spray Drying (SD). The milk contains high water content and other major ingredients like fat, protein, lactose, and minerals. Although many types of dietary lipids are present, fat present in milk is very much complicated as it is comprised of more than one hundred different types of FAs and numerous triglycerides. Huge varieties of triglycerides and FAs structure enable the possibility to categorize MF into different fractions on the grounds of their melting abilities. Functional characteristics of MF can be increased by converting it into different fractions [44]. The composition of the milk by itself plays a major role in the drying rate and the functional properties of the final product. FAs analysis of MS has shown very low EPA $0.044 \pm 0.01 \%$ and DHA $0.006 \pm 0.01 \%$ content among the PUFAs group of total FAs present in MF (Table 2). The findings of the present study are supported by the research work of Stergiadis et al. [45] which described that the cow milk has very low percentages of the EPA and DHA as $0.048 \%$ and $0.007 \%$, respectively, among PUFAs groups. Mainly, milk FAs have been focused on from research point of view as milk FAs respond quickly and they are sensitive in nature. Moreover, the farming practices also produce their results on FAs composition of milk. Recently, the chemical characteristics and changes in milk FAs during storage are central areas of dairy development and research. Different aspects that affect the variation in milk FAs are energy status, animal breed, lactation time, and time of season and the most important is udder health [46]. Also, the PV of drawn MF is mentioned in Table 2, which indicated that the PV of MF was $0.5 \pm 0.02 \mathrm{meqO}_{2} / \mathrm{kg}$ of MF. The PV of MF is in agreement with the results reported by Ajmal et al. [47]. The $\mathrm{PV}$ in the $\mathrm{FO}$ was found to be $1.75 \pm 0.13 \mathrm{meqO}_{2} / \mathrm{kg}$ and this reported value is very near to the value of the $\mathrm{FO}$ which was $0.92 \mathrm{meqO}_{2} / \mathrm{kg}$ [48]. FAs of extracted FO were EPA $\mathrm{C}_{20: 5}$ $7.19 \pm 0.51$ and DHA $C_{22: 6} 8.21 \pm 0.69$ as \% of PUFA group presented in Table 2. The FO contained DHA $8.30 \%$ of PUFAs and EPA content as $7.23 \%$ of PUFAs, respectively [49].

3.2. $S D$ of $M F O B$. The MFOB was spray dried to produce SDP by using mini spray dryer (TPS-15 Lab Spray Dryer, China). The treatment plan of operating drying conditions was based upon central composite design (Table 1). In this research work, response surface methodology (RSM) was applied to surface the optimal SD conditions for MFOB samples. The impacts of four independent variables of spray dryer, that is, IAT $\left(160^{\circ} \mathrm{C}, 180^{\circ} \mathrm{C}\right.$, and $\left.200^{\circ} \mathrm{C}\right)$, PS $(3 \mathrm{~mL} / \mathrm{min}$, $6 \mathrm{~mL} / \mathrm{min}$, and $9 \mathrm{~mL} / \mathrm{min}), \mathrm{MD}(10 \%, 20 \%$, and $30 \%)$ and $\mathrm{NS}$ $(5 \mathrm{~s}, 7 \mathrm{~s}$, and $9 \mathrm{~s})$, were extensively studied for SD effect on MFOB, their omega FAs composition, and primary
TABLE 2: Characterization of milk fat and fish oil samples.

\begin{tabular}{lccc}
\hline Sample & $\begin{array}{c}\text { EPA (\% of } \\
\text { PUFAs) }\end{array}$ & $\begin{array}{c}\text { DHA (\% of } \\
\text { PUFAs) }\end{array}$ & $\begin{array}{c}\mathrm{PV}\left(\mathrm{meqO}_{2} /\right. \\
\mathrm{kg})\end{array}$ \\
\hline MF & $0.044 \pm 0.01$ & $0.006 \pm 0.01$ & $0.5 \pm 0.02$ \\
FO & $7.19 \pm 0.51$ & $8.21 \pm 0.69$ & $1.75 \pm 0.13$ \\
\hline
\end{tabular}

$\mathrm{Mf}=$ milk fat; $\quad \mathrm{FO}=$ fish oil; $\quad \mathrm{EPA}=$ eicosapentaenoic $\quad$ acid; DHA = docosahexaenoic acid; PUFAs = polyunsaturated fatty acids; $\mathrm{PV}=$ peroxide value. The MFOB samples possessed the EPA $2.24 \pm 0.16$ (g/ $100 \mathrm{~g}$ extracted fat) and DHA $3.33 \pm 0.18$ (g/100 g extracted fat), while PV was $1.44 \pm 0.11 \mathrm{meqO}_{2} / \mathrm{kg}$.

oxidative stability. The effects of these four factors and their three respective levels were expressed through polynomial regression equations. In the dairy industry, lipid oxidation has always been a major problem. The bioactive substance such as MF can be packed by SD technique within a WM. Emulsion should be stable as it is one of the key properties for SDP making with lower levels of free fat over surface of powder particles. Tan [50] used the sodium caseinate (NaCas) as WM for development of oil-in-water $(\mathrm{O} / \mathrm{W})$ emulsions. The SD operating factors such as IAT, drying air (DA) flow rate, atomization pressure, total solid level of the material, viscosity, and nozzles type are key important to observe and understand. On the other side, composition of the milk also contributes as critical factor to the drying process and the functional characteristics of end product. A whole milk is generally described as a colloidal system, where components like fats, proteins, salts, and lactose make a complex system with water present in milk. The MF is a type of emulsion like oil-in-water and is organized in a globular structure, while the proteins exhibit as colloidal components and make micellar forms [51, 52]. After the completion of SD process, the milk is generally collected as a powder in a collection chamber. Powder yield in the cyclone will be higher with increase in IAT and DA flow speed. This process can be explained as when DA flow rate increases, it speeds up the movement of moisture from the droplet into the DA, which obviously results in increased thermal energy and heat transfer coefficients. Interestingly, powder recovery has been observed to decrease with increase in concentration of milk solid particles at constant DA flow rate. Increased viscosity of feed produced difficulty to flow of raw liquid in feeding tube and resultantly atomization of the liquid through the narrow orifice becomes tough. Moreover, the sticky final product is produced when operating conditions are not properly controlled or optimized [53].

3.3. Optimization of SD Conditions. Most of the times in RSM models, the nature of the relationship among the independent factors/variables and output responses is not known. However, the very first thing in RSM is to determine an appropriate relationship among dependent and independent variables [54]. RSM was employed to optimize independent variables on the EE and retention of EPA and DHA. The experimental design based on the CCD was used to study the effects of independent factors on defined responses. A typical SD procedure is shown in Figure 1. A total of 30 runs were conducted in triplicate. The average mean of 
performed triplicate runs of optimized response was reported as the measured value with the standard deviation. Table 3 shows the conducted runs with the optimized responses.

3.4. Fitting the Proposed Model. Predicted values for response variables were determined through regression model. These values were analyzed to compare values of responses for verification and validity of second-order polynomial responses. The predicted values of response variables were observed in the same range of reported experimental values. The statistical results of quadratic model for response variables have been shown in Table 4. Several indicators were noted such as coefficient of determination $\left(R^{2}\right)$ which ranged between 0.5798 and 0.9022 for response variables. The $R^{2}$ value which is near 1 shows that the model is reproducible. Adequate precision ratio tells the level of adequacy of the model and a ratio more than 4 is considered best. The ratio for response variables ranged between 10.937 and 14.972. This value was considered to navigate the design space. The model regression equations comprising both of coded and actual levels using response surface methodology (CCD) have been documented in Table 5 .

3.5. Encapsulation Efficiency (EE) of SDP. The EE ranged between 89.30 and $81.57 \%$. The highest results for response EE (89.30\%) were observed at spray dryer run no. 26, where independent variables (IAT was $160^{\circ} \mathrm{C}$, PS was $9 \mathrm{~mL} / \mathrm{min}$, MD was $30 \%$, and NS was 9 s) were set to study response. The spray dryer run no. 9 (IAT was $200^{\circ} \mathrm{C}$, PS was $3 \mathrm{~mL} / \mathrm{min}$, MD was $10 \%$, and NS was $5 \mathrm{~s}$ ) produced lowest response values of $\mathrm{EE}$ as $81.57 \%$. It has been documented that the liquid conversion to powder by SD ensures quality aspects and safety concerns of final powder. However, the uncontrolled processing conditions at extreme levels impart negative affect on SDP, alter the product value, and are responsible for the losses of valuable nutritional components [29]. Thermal dehydration has been reported as the best and cost-effective method that is normally used for food storage [55]. SD is still the one of the best drying methods that have significant potential for the food processing industries [56]. The factors including IAT, PS, WM, and NS were observed to develop the optimized drying conditions. The relationship among these variables for EE is shown in Figure 2. During the SD method, the core material is housed within the WM. The formation of SDP and the properties of WM are critical aspects for the EE and stability properties of SDP [57]. The EE depends significantly on temperature condition. The evaporation was significant at IAT $\left(160^{\circ} \mathrm{C}\right)$, which resulted in EE up to $89.30 \%$. It shows that, at that temperature, the drying rate of particles was optimized, and particles were uniformly sprayed in cyclone, and further SDP was collected in collection bottle. Also, significant effect on EE was noted on the increase of wall material concentration and at low temperature. It was observed that higher temperature affected the outer layer formation in powder particles. Aghbashlo et al. [58] documented EE of FO as $81.94 \%$ using WM separated from milk and EE was significantly influenced by temperature of DA in cyclone chamber. Moreover, it was noted that the SD process at optimized conditions did not negatively affect the efficiency of oil encapsulation. The drying phenomena of material at optimized conditions helped in the quick formation of surface/crust of SDP. Furthermore, the rate of crust formation was high, which gave protection against oil leaching from SDP. Similarly, Wu [59] described in detail that the temperature conditions significantly affect wall material. At the high IAT, undesired evaporation occurs and causes the cracks formation on the outermost layer of SDP, which leads towards release of core matter and its deterioration. The same trend was observed in the present study as when IAT was $200^{\circ} \mathrm{C}$, EE was lower when compared with EE at other IAT treatments (Table 3). EE also depends on the composition of the samples [60]. Also, wall material at 30\% concentration limited the oil diffusion on the particle's surface, which is also considered a contributing factor towards the optimum EE. Aghbashlo et al. [58] used the combination of wall materials for FO encapsulation and observed that the viscosity increased during blend formation and produced the powder with best EE. Other operating independent variables such as NS and PS are also contributing factors. It is noteworthy to mention that the low NS and high PS operating conditions lead to increased liquid flow through atomizer and caused bigger particle size formation. Proper homogenization of WM and oil contents during blend formation also affect the PS and SD process. It has also been noted that the decrease in quantity of oil matter during homogenization of blend leads to speedy crust formation. Furthermore, the semipermeable encapsulate droplets were formed, which was maybe due to WM layer during the SD technique. The quick formation of protecting layer reduced the oil leaching from SDP and ultimately enhanced the EE [61]. PS at $9 \mathrm{~mL} / \mathrm{min}$ and NS of $9 \mathrm{~s}$ in combination with IAT at $160^{\circ} \mathrm{C}$ relatively were best to achieve quick evaporation and to avoid cracks on wall material and ultimately produced best EE results. Similar type of optimized relationship between NS and PS for best spray drying pattern was discussed by Amaro et al. [62] to achieve highest EE of the resultant samples.

3.6. Eicosapentaenoic Acid and Docosahexaenoic Acid Retention and Losses. Spray drying operating conditions should be optimized to ensure maximum retention of nutritional components in milk and technofunctional aspects of the SDP. The present work was based on studying the effects of independent parameters on the SDP production and selected nutritional composition as response variables of SDP. However, retaining of nutritional ingredients is a key factor that should be considered during processing and preservation of food. When SD technique is applied on milk, the powder recovery and FAs retention are affected based on changing levels in temperature and atomization pressure [53]. The effects of SD parameters related to percent loss of EPA and DHA have been explained in Figures 3 and 4, respectively. The EPA and DHA retentions were in the ranges of $2.19-1.87 \mathrm{~g} / 100 \mathrm{~g}$ and $3.20-2.75 \mathrm{~g} / 100 \mathrm{~g}$, respectively, being the highest to lowest among all 30 runs. The highest results for responses are shown at spray dryer run no. 26 where independent variables (IAT was $160^{\circ} \mathrm{C}$, PS was $9 \mathrm{~mL} /$ 
TABLE 3: Effect of spray drying conditions on the response parameters.

\begin{tabular}{|c|c|c|c|c|c|c|c|c|c|c|}
\hline \multirow{2}{*}{$\begin{array}{l}\text { Spray } \\
\text { drying } \\
\text { run }\end{array}$} & \multicolumn{4}{|c|}{$\begin{array}{l}\text { Independent variable } \\
\text { combination }\end{array}$} & \multicolumn{6}{|c|}{ Response parameters } \\
\hline & $\begin{array}{l}\text { IAT } \\
\left({ }^{\circ} \mathrm{C}\right)\end{array}$ & $\begin{array}{l}\text { PS } \\
(\mathrm{mL} / \\
\mathrm{min})\end{array}$ & $\begin{array}{l}\text { MD } \\
(\%)\end{array}$ & $\begin{array}{l}\text { NS } \\
(\mathrm{s})\end{array}$ & $\mathrm{EE}(\%)$ & $\begin{array}{l}\text { EPA retained } \\
\quad(\mathrm{g} / 100 \mathrm{~g} \\
\text { extracted fat })\end{array}$ & $\begin{array}{c}\text { EPA loss } \\
(\%)\end{array}$ & $\begin{array}{l}\text { DHA retained } \\
\quad(\mathrm{g} / 100 \mathrm{~g} \\
\text { extracted fat })\end{array}$ & $\begin{array}{c}\text { DHA loss } \\
(\%)\end{array}$ & $\begin{array}{c}\mathrm{PV} \\
\left(\mathrm{meqO}_{2 /} \mathrm{kg}\right)\end{array}$ \\
\hline 1 & $200(+1)$ & $3(-1)$ & $10(-1)$ & $9(+1)$ & $81.99 \pm 1.78$ & $1.88 \pm 0.14$ & $16.07 \pm 0.23$ & $2.78 \pm 0.15$ & $16.70 \pm 0.21$ & $2.10 \pm 0.10$ \\
\hline 2 & $180(0)$ & $6(0)$ & $20(0)$ & $5(-1)$ & $84.93 \pm 1.67$ & $2.03 \pm 0.15$ & $9.37 \pm 0.28$ & $2.99 \pm 0.12$ & $10.38 \pm 0.23$ & $1.98 \pm 0.13$ \\
\hline 3 & $200(+1)$ & $3(-1)$ & $30(+1)$ & $9(+1)$ & $82.33 \pm 1.45$ & $1.92 \pm 0.15$ & $14.28 \pm 0.25$ & $2.81 \pm 0.13$ & $15.82 \pm 0.19$ & $2.09 \pm 0.14$ \\
\hline 4 & $160(-1)$ & $9(+1)$ & $10(-1)$ & $5(-1)$ & $84.82 \pm 1.54$ & $2.03 \pm 0.16$ & $9.37 \pm 0.22$ & $2.97 \pm 0.15$ & $10.97 \pm 0.25$ & $1.93 \pm 0.11$ \\
\hline 5 & $180(0)$ & $3(-1)$ & $20(0)$ & $7(0)$ & $85.91 \pm 1.96$ & $2.07 \pm 0.15$ & $7.58 \pm 0.24$ & $3.03 \pm 0.19$ & $9.20 \pm 0.26$ & $1.95 \pm 0.12$ \\
\hline 6. $(\mathrm{C} 1)$ & $180(0)$ & $6(0)$ & $20(0)$ & $7(0)$ & $85.77 \pm 1.76$ & $2.09 \pm 0.16$ & $6.69 \pm 0.26$ & $3.07 \pm 0.13$ & $8.02 \pm 0.23$ & $1.94 \pm 0.10$ \\
\hline 7 & $200(+1)$ & $3(-1)$ & $30(+1)$ & $5(-1)$ & $83.37 \pm 1.40$ & $1.97 \pm 0.14$ & $12.05 \pm 0.27$ & $2.89 \pm 0.19$ & $13.32 \pm 0.25$ & $2.07 \pm 0.12$ \\
\hline 8. (C2) & $180(0)$ & $6(0)$ & $20(0)$ & $7(0)$ & $85.93 \pm 1.87$ & $2.07 \pm 0.14$ & $7.58 \pm 0.25$ & $3.03 \pm$ & $9.20 \pm 0.28$ & $1.96 \pm 0.14$ \\
\hline 9 & $200(+1)$ & $3(-1)$ & $10(-1)$ & $5(-1)$ & $81.57 \pm 1.78$ & $1.87 \pm 0.15$ & $16.51 \pm 0.28$ & $2.75 \pm 0.15$ & $17.44 \pm 0.28$ & $2.20 \pm 0.17$ \\
\hline 10 & $160(-1)$ & $3(-1)$ & $30(+1)$ & $5(-1)$ & $88.21 \pm 1.92$ & $2.17 \pm 0.17$ & $3.12 \pm 0.19$ & $3.18 \pm 0.14$ & $4.79 \pm 0.20$ & $1.91 \pm 0.12$ \\
\hline 11 & $200(+1)$ & $9(+1)$ & $30(+1)$ & $9(+1)$ & $82.04 \pm 1.96$ & $1.89 \pm 0.13$ & $15.62 \pm 0.20$ & $2.80 \pm 0.17$ & $15.97 \pm 0.23$ & $2.08 \pm 0.13$ \\
\hline 12 & $180(0)$ & $6(0)$ & $30(+1)$ & $7(0)$ & $88.31 \pm 1.56$ & $2.17 \pm 0.17$ & $3.12 \pm 0.24$ & $3.18 \pm 0.12$ & $4.50 \pm 0.26$ & $1.99 \pm 0.13$ \\
\hline 13 & $160(-1)$ & $3(-1)$ & $10(-1)$ & $5(-1)$ & $85.34 \pm 1.89$ & $2.04 \pm 0.16$ & $8.92 \pm 0.27$ & 15 & $10.35 \pm 0.24$ & $1.92 \pm 0.15$ \\
\hline 14 & $160(-1)$ & $9(+1)$ & $10(-1)$ & $9(+1)$ & $86.79 \pm 1.87$ & $2.09 \pm 0.17$ & $6.69 \pm 0.20$ & $3.09 \pm 0.16$ & $7.43 \pm 0.25$ & $1.89 \pm 0.15$ \\
\hline 15 & $160(-1)$ & $9(+1)$ & $30(+1)$ & $5(-1)$ & $86.81 \pm 1.84$ & $2.10 \pm 0.15$ & $6.25 \pm 0.28$ & $3.09 \pm 0.17$ & $7.29 \pm 0.24$ & $1.90 \pm 0.15$ \\
\hline 16 & $180(0)$ & $9(+1)$ & $20(0)$ & $7(0)$ & $85.33 \pm 1.39$ & $2.09 \pm 0.15$ & $6.69 \pm 0.22$ & & $8.02 \pm 0.26$ & $1.95 \pm 0.11$ \\
\hline 17. (C3) & $180(0)$ & $6(0)$ & $20(0)$ & $7(0)$ & $85.45 \pm 1$ & & & & & $1.96 \pm$ \\
\hline 18. (C4) & $180(0)$ & $6(0)$ & $20(0)$ & $7(0)$ & $83.40 \pm 1.30$ & $1.99 \pm 0.14$ & $11.16 \pm 0.20$ & $2.92 \pm 0.14$ & $12.44 \pm 0.26$ & $1.94 \pm 0.14$ \\
\hline 19. (C5) & $180(0)$ & $6(0)$ & $20(0)$ & $7(0)$ & $85.28 \pm 1.45$ & $2.08 \pm 0.18$ & $7.14 \pm 0.27$ & $3.06 \pm 0.10$ & $8.17 \pm 0.24$ & $1.95 \pm 0.10$ \\
\hline 20 & $200(+1)$ & $9(+1)$ & $30(+1)$ & $5(-1)$ & $82.76 \pm 1.67$ & $1.93 \pm 0.16$ & $13.83 \pm 0.24$ & $2.85 \pm 0.17$ & $14.50 \pm 0.27$ & $2.10 \pm 0.10$ \\
\hline 21 & $160(-1)$ & $6(0)$ & $20(0)$ & $7(0)$ & $87.34 \pm 1.47$ & $2.13 \pm 0.15$ & $4.91 \pm 0.26$ & $3.13 \pm 0.15$ & $6.26 \pm 0.27$ & $1.90 \pm 0.13$ \\
\hline 22 & $160(-1)$ & $3(-1)$ & $30(+1)$ & $9(+1)$ & $87.94 \pm 1.87$ & $2.14 \pm 0.15$ & $4.46 \pm 0.26$ & $3.13 \pm 0.15$ & $6.11 \pm 0.25$ & $1.91 \pm 0.11$ \\
\hline 23 & $200(+1)$ & $9(+1)$ & $10(-1)$ & $5(-1)$ & $82.21 \pm 1.98$ & $1.93 \pm 0.15$ & $13.80 \pm 0.25$ & $2.82 \pm 0.11$ & $15.38 \pm 0.24$ & $2.10 \pm 0.16$ \\
\hline 24 & $160(-1)$ & $3(-1)$ & $10(-1)$ & $9(+1)$ & $84.57 \pm 1.76$ & $2.02 \pm 0.14$ & $9.82 \pm 0.24$ & $2.98 \pm 0.12$ & $10.52 \pm 0.26$ & $1.89 \pm 0.14$ \\
\hline 25 & $180(0)$ & $6(0)$ & $20(0)$ & $9(+1)$ & $87.94 \pm 1.56$ & $2.14 \pm 0.15$ & $4.46 \pm 0.27$ & $3.13 \pm 0.12$ & $6.11 \pm 0.26$ & $1.90 \pm 0.14$ \\
\hline 26 & $160(-1)$ & $9(+1)$ & $30(+1)$ & $9(+1)$ & $89.30 \pm 1.54$ & $2.19 \pm 0.11$ & $2.23 \pm 0.26$ & $3.20 \pm 0.12$ & $3.90 \pm 0.23$ & $1.88 \pm 0.16$ \\
\hline 27 & $200(+1)$ & $9(+1)$ & $10(-1)$ & $9(+1)$ & $83.40 \pm 1.43$ & $1.99 \pm 0.12$ & $11.16 \pm 0.23$ & $2.92 \pm 0.14$ & $12.44 \pm 0.20$ & $2.09 \pm 0.15$ \\
\hline 28. (C6) & $180(0)$ & $6(0)$ & $20(0)$ & $7(0)$ & $85.30 \pm 1.93$ & $2.07 \pm 0.11$ & $7.58 \pm 0.23$ & $3.02 \pm 0.18$ & $9.50 \pm 0.25$ & $1.95 \pm 0.13$ \\
\hline 29 & $200(+1)$ & $6(0)$ & $20(0)$ & $7(0)$ & $82.14 \pm 1.45$ & $1.92 \pm 0.14$ & $14.28 \pm 0.21$ & $2.82 \pm 0.19$ & $15.53 \pm 0.26$ & $2.09 \pm 0.12$ \\
\hline 30 & $180(0)$ & $6(0)$ & $10(-1)$ & $7(0)$ & $84.10 \pm 1.65$ & $2.01 \pm 0.14$ & $10.26 \pm 0.20$ & $1.98 \pm 0.14$ & $10.57 \pm 0.25$ & $1.97 \pm 0.10$ \\
\hline
\end{tabular}

$\mathrm{C} 1-\mathrm{C} 6=$ central points of spray drying runs; IAT = inlet air temperature; $\mathrm{PS}=$ pump speed; $\mathrm{MD}=$ maltodextrin; $\mathrm{NS}=$ needle speed; $\mathrm{EE}=$ encapsulation efficiency; $\mathrm{EPA}=$ eicosapentaenoic acid; $\mathrm{DHA}=$ docosahexaenoic acid; $\mathrm{PV}=$ peroxide value .

min, $\mathrm{MD}$ was $30 \%$, and NS was 9 s) were set to study responses. The maximum results related to EPA and DHA retention were $2.19 \mathrm{~g} / 100 \mathrm{~g}$ and $3.20 \mathrm{~g} / 100 \mathrm{~g}$, respectively. The spray dryer run no. 9 (IAT was $200^{\circ} \mathrm{C}$, PS was $3 \mathrm{~mL} / \mathrm{min}, \mathrm{MD}$ was $10 \%$, and NS was $5 \mathrm{~s}$ ) produced the lowest values of EPA and DHA retained as $1.87 \mathrm{~g} / 100 \mathrm{~g}$ and $2.75 \mathrm{~g} / 100 \mathrm{~g}$, respectively. The overall percent losses of EPA and DHA were examined in the range of $2-18 \%$. The IAT was observed as main factor for FAs losses. These finding are further supported by De Oliveira et al.'s [29] study in which they reported the impact of SD conditions on milk FAs and noted that the low drying period and IAT were nonsignificant for thermal degradation. Furthermore, in another study, Lavanya et al. [63] documented the effects of SD conditions on EPA (13.64\%) and DHA (32.46\%) content in FO, which were decreased to $12.48 \%$ (EPA) and $30.58 \%$ (DHA) after the SD, respectively.

3.7. Oxidative Stability of SDP. The key focus of SDP development was making the protective layer around the core material (FO). This WM layer may protect the core material from external undesirable conditions and lipid oxidation. Previous studies reported that the SD of FO enhanced its stability. Among the SD variables, the heat is considered as key factor that can enhance chances of lipids oxidation [64]. Further, the PV is determined to estimate the primary oxidation components [65]. The PVs of all SD runs are detailed in Table 3. Lowest PV was noticed at run no. 26 which was $1.88 \mathrm{meqO}_{2} / \mathrm{kg}$ and highest $\mathrm{PV}$ of $2.20 \mathrm{meqO}_{2} / \mathrm{kg}$ was observed at run no. 9. The mutual interaction impact of SD conditions on PV of SDP samples has been presented in Figure 5. Santhanam et al. [41] produced dried powder from fish oil and milk blend using sodium caseinate as WM by SD process. The PVs of produced SDP samples were within the range of $3-10 \mathrm{meqO}_{2} / \mathrm{kg}$ at room temperature during the storage interval of 0-32 days. Aghbashlo et al. [58] noted the $\mathrm{PV}$ of $\mathrm{FO}$ as $5 \mathrm{meqO}_{2} / \mathrm{kg}$ which was further increased to $7 \mathrm{meqO}_{2} / \mathrm{kg}$ after SD. One of the known reasons for this increase in PV was the heating factor. Serfert et al. [66] reported their findings related to SD procedure and its effects on lipids. They discussed that the PV of lipids increased with rise in IAT and produced more peroxides which 
TABLE 4: Analysis of variance (ANOVA) of the predicted second-order polynomial model for spray drying conditions' impact on response parameters.

\begin{tabular}{|c|c|c|c|c|c|c|c|c|c|c|}
\hline \multirow{3}{*}{\multicolumn{2}{|c|}{ Source of variation }} & \multirow{3}{*}{$\mathrm{df}$} & \multicolumn{8}{|c|}{ Response parameters } \\
\hline & & & \multicolumn{2}{|c|}{$\mathrm{EE}(\%)$} & \multicolumn{2}{|c|}{$\begin{array}{c}\text { EPA retained }(\mathrm{g} / 100 \mathrm{~g} \\
\text { extracted fat })\end{array}$} & \multicolumn{2}{|c|}{$\begin{array}{l}\text { DHA retained }(\mathrm{g} / 100 \mathrm{~g} \\
\text { extracted fat) }\end{array}$} & \multicolumn{2}{|c|}{$\mathrm{PV}\left(\mathrm{meqO}_{2 / \mathrm{kg}}\right)$} \\
\hline & & & Mean square & $p$ value & Mean square & $p$ value & Mean square & $p$ value & Mean square & $p$ value \\
\hline Model & & 14 & $8.74^{* *}$ & 0.0001 & $0.0155^{* *}$ & $<0.0001$ & $0.0609^{\mathrm{NS}}$ & 0.2306 & $0.0148^{* *}$ & $<0.0001$ \\
\hline \multirow{4}{*}{ Linear effects } & A-IAT & 1 & $85.85^{* *}$ & $<0.0001$ & $0.1440^{* *}$ & $<0.0001$ & $0.2990^{*}$ & 0.0167 & $0.1780^{* *}$ & $<0.0001$ \\
\hline & B-PS & 1 & $0.2763^{\mathrm{NS}}$ & 0.6183 & $0.0014^{\mathrm{NS}}$ & 0.3566 & $0.0041^{\mathrm{NS}}$ & 0.7582 & $0.0008^{\mathrm{NS}}$ & 0.2253 \\
\hline & C-MD & 1 & $14.72^{* *}$ & 0.0021 & $0.0214^{* *}$ & 0.0022 & $0.1901^{*}$ & 0.0485 & $0.0014^{\mathrm{NS}}$ & 0.1124 \\
\hline & D-NS & 1 & $2.19^{\mathrm{NS}}$ & 0.1724 & $0.0020^{\mathrm{NS}}$ & 0.2765 & $0.0053^{\mathrm{NS}}$ & 0.7239 & $0.0044^{* *}$ & 0.0099 \\
\hline \multirow{6}{*}{ Interaction effects } & AB & 1 & $0.0163^{\mathrm{NS}}$ & 0.9034 & $0.0002^{\mathrm{NS}}$ & 0.7105 & $0.0005^{\mathrm{NS}}$ & 0.9132 & $0.0002^{\mathrm{NS}}$ & 0.5126 \\
\hline & AC & 1 & $5.53^{*}$ & 0.0379 & $0.0090^{*}$ & 0.0301 & $0.0150^{\mathrm{NS}}$ & 0.5552 & $0.0009^{\mathrm{NS}}$ & 0.1997 \\
\hline & AD & 1 & $0.7966^{\mathrm{NS}}$ & 0.4012 & $0.0009^{\mathrm{NS}}$ & 0.4610 & $0.0018^{\mathrm{NS}}$ & 0.8370 & $0.0000^{\mathrm{NS}}$ & 0.8261 \\
\hline & BC & 1 & $1.37^{\mathrm{NS}}$ & 0.2742 & $0.0064^{\mathrm{NS}}$ & 0.0619 & $0.0086^{\mathrm{NS}}$ & 0.6552 & $0.0004^{\mathrm{NS}}$ & 0.3853 \\
\hline & BD & 1 & $2.71^{\mathrm{NS}}$ & 0.1316 & $0.0042^{\mathrm{NS}}$ & 0.1220 & $0.0095^{\mathrm{NS}}$ & 0.6380 & $0.0000^{\mathrm{NS}}$ & 0.8261 \\
\hline & CD & 1 & $0.3452^{\mathrm{NS}}$ & 0.5780 & $0.0012^{\mathrm{NS}}$ & 0.3913 & $0.0060^{\mathrm{NS}}$ & 0.7080 & $0.0016^{\mathrm{NS}}$ & 0.0939 \\
\hline \multirow{4}{*}{ Quadratic effects } & $\mathrm{A}^{2}$ & 1 & $4.03^{\mathrm{NS}}$ & 0.0711 & $0.0094^{*}$ & 0.0272 & $0.0073^{\mathrm{NS}}$ & 0.6804 & $0.0045^{* *}$ & 0.0088 \\
\hline & $\mathbf{B}^{2}$ & 1 & $0.3485^{\mathrm{NS}}$ & 0.5762 & $0.0001^{\mathrm{NS}}$ & 0.8337 & $0.0424^{\mathrm{NS}}$ & 0.3263 & $0.0000^{\mathrm{NS}}$ & 0.8233 \\
\hline & $\mathrm{C}^{2}$ & 1 & $0.1234^{\mathrm{NS}}$ & 0.7385 & $0.0001^{\mathrm{NS}}$ & 0.8501 & $0.3031^{*}$ & 0.0161 & $0.0019^{\mathrm{NS}}$ & 0.0725 \\
\hline & $\mathrm{D}^{2}$ & 1 & $0.5206^{\mathrm{NS}}$ & 0.4956 & $1.794 E-07^{\mathrm{NS}}$ & 0.9916 & $0.0493^{\mathrm{NS}}$ & 0.2912 & $0.0004^{\mathrm{NS}}$ & 0.3586 \\
\hline \multicolumn{2}{|l|}{ Residual } & 15 & 1.07 & - & 0.0016 & - & 0.0412 & - & 0.0005 & - \\
\hline \multicolumn{2}{|l|}{ Lack of fit } & 10 & $1.18^{\mathrm{NS}}$ & 0.3677 & $0.0017^{\mathrm{NS}}$ & 0.3923 & $0.0604^{* *}$ & 0.0018 & $0.0007^{*}$ & 0.0132 \\
\hline \multicolumn{2}{|l|}{ Pure error } & 5 & 0.8352 & - & 0.0013 & - & 0.0029 & - & 0.0001 & - \\
\hline \multicolumn{2}{|l|}{ Cor. total } & 29 & - & - & - & - & - & - & - & - \\
\hline
\end{tabular}

*, ** Significant at 0.05 level; IAT =inlet air temperature; PS=pump speed; $\mathrm{MD}=$ maltodextrin; $\mathrm{NS}=$ needle speed; $\mathrm{EE}=$ encapsulation efficiency; $\mathrm{EPA}=$ eicosapentaenoic acid; $\mathrm{DHA}=$ docosahexaenoic acid; $\mathrm{PV}=$ peroxide value.

TABLE 5: Coded and actual regression equations for response parameters after spray drying process.

\begin{tabular}{|c|c|c|}
\hline $\begin{array}{l}\text { Response } \\
\text { parameter }\end{array}$ & $\begin{array}{l}\text { Regression } \\
\text { form }\end{array}$ & Regression equation \\
\hline \multirow{4}{*}{$\mathrm{EE}$} & Coded & $\begin{array}{c}R 1=+85.59-2.18 \mathrm{~A}+0.1239 \mathrm{~B}+0.9044 \mathrm{C}+0.3489 \mathrm{D}-0.0319 \mathrm{AB}-0.5881 \mathrm{AC}-0.2231 \mathrm{AD}-0.2931 \mathrm{BC}+0.4119 \mathrm{BD}- \\
0.1469 \mathrm{CD}-1.25 \mathrm{~A}^{2}-0.3668 \mathrm{~B}^{2}+0.2182 \mathrm{C}^{2}+0.4482 \mathrm{D}^{2}\end{array}$ \\
\hline & & $R 1=-11.63130+1.11393 \mathrm{IAT}+0.051123 \mathrm{PS}+0.642490 \mathrm{MD}-0.655353 \mathrm{NS}-0.000080 \mathrm{IAT}^{*} \mathrm{PS}-$ \\
\hline & Actual & 0.002941IAT* MD-0.005578IAT*NS-0.001466PS* MD + 0.010297PS*NS-0.007344MD*NS-0.003117IAT ${ }^{2}-$ \\
\hline & & $0.000917 \mathrm{PS}^{2}+0.002182 \mathrm{MD}^{2}+0.112061 \mathrm{NS}^{2}$ \\
\hline \multirow{4}{*}{$\begin{array}{l}\text { EPA } \\
\text { retention }\end{array}$} & Code & $R 2=+2.07-0.0894 \mathrm{~A}+0.0089 \mathrm{~B}+0.0344 \mathrm{C}+0.0106 \mathrm{D}+0.0038 \mathrm{AB}-0.0238 \mathrm{AC}-0.0075 \mathrm{AD}-$ \\
\hline & & $0.0200 \mathrm{BC}+0.0163 \mathrm{BD}-0.0087 \mathrm{CD}-0.0603 \mathrm{~A}^{2}-0.0053 \mathrm{~B}^{2}+0.0047 \mathrm{C}^{2}-0.0003 \mathrm{D}^{2}$ \\
\hline & & $637+0.053077 \mathrm{IAT}-0.001034 \mathrm{PS}+0.029987 \mathrm{MD}+0.032449 \mathrm{NS}+9.37500 \mathrm{E}-06 \mathrm{IAT}^{*} \mathrm{I}$ \\
\hline & Actual & $\begin{array}{l}0.000119 \mathrm{IAT}^{*} \mathrm{MD}-0.000188 \mathrm{IAT}^{*} \mathrm{NS}-0.000100 \mathrm{PS}^{*} \mathrm{MD}+0.000406 \mathrm{PS}^{*} \mathrm{NS}-0.000438 \mathrm{MD}^{*} \mathrm{NS}-0.000151 \mathrm{IAT}^{2}- \\
0.000013 \mathrm{PS}^{2}+0.000047 \mathrm{MD}^{2}-0.000066 \mathrm{NS}^{2}\end{array}$ \\
\hline \multirow{5}{*}{$\begin{array}{l}\text { DHA } \\
\text { retention }\end{array}$} & & \\
\hline & Coded & $R 3=+2.97-0.1289 \mathrm{~A}+0.0150 \mathrm{~B}+0.1028 \mathrm{C}+0.0172 \mathrm{D}+0.0056 \mathrm{AB}-0.0306 \mathrm{AC}-0.0106 \mathrm{AD}-$ \\
\hline & & $R 3=+8.11788-0.049769 \mathrm{IAT}-0.029331 \mathrm{PS}+0.186054 \mathrm{MD}-0.431515 \mathrm{NS}+0.000014 \mathrm{IAT} * \mathrm{PS}-$ \\
\hline & Actual & $0.000153 \mathrm{IAT}^{*} \mathrm{MD}-0.000266 \mathrm{IAT}^{*} \mathrm{NS}-0.000116 \mathrm{PS}^{*} \mathrm{MD}+0.000609 \mathrm{PS}{ }^{*} \mathrm{NS}-$ \\
\hline & & $0.000969 \mathrm{MD}^{*} \mathrm{NS}+0.000132 \mathrm{IAT}^{2}+0.000320 \mathrm{PS}^{2}-0.003420 \mathrm{MD}^{2}+0.034496 \mathrm{NS}^{2}$ \\
\hline \multirow{6}{*}{ PV } & Coded & $R 4=+1.95+0.0994 \mathrm{~A}-0.0067 \mathrm{~B}-0.0089 \mathrm{C}-0.0156 \mathrm{D}-0.0037 \mathrm{AB}-0.0075 \mathrm{AC}-$ \\
\hline & Loded & $0.0012 \mathrm{AD}+0.0050 \mathrm{BC}+0.0013 \mathrm{BD}+0.0100 \mathrm{CD}+0.0418 \mathrm{~A}^{2}-0.0032 \mathrm{~B}^{2}+0.0268 \mathrm{C}^{2}-0.0132 \mathrm{D}^{2}$ \\
\hline & & $R 4=+4.32177-0.031342 \mathrm{IAT}+0.001267 \mathrm{PS}-0.009376 \mathrm{MD}+0.032650 \mathrm{NS}-9.37500 E-06 \mathrm{IAT}^{*} \mathrm{PS}-$ \\
\hline & Actual & 0.000037IAT* MD- \\
\hline & & $0.000031 \mathrm{IAT}^{*} \mathrm{NS}+0.000025 \mathrm{PS}^{*} \mathrm{MD}+0.000031 \mathrm{PS}^{*} \mathrm{NS}+0.000500 \mathrm{MD}^{*} \mathrm{NS}+0.000105 \mathrm{IAT}^{2}-$ \\
\hline & & 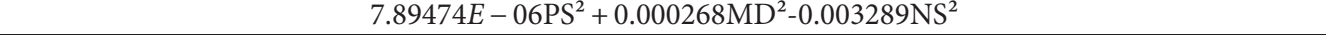 \\
\hline
\end{tabular}

$A$ : IAT = inlet air temperature; $B: \mathrm{PS}=$ pump speed; $C: \mathrm{MD}=$ maltodextrin; $D: \mathrm{NS}=$ needle speed. $\mathrm{EE}=$ encapsulation efficiency; $\mathrm{EPA}=$ eicosapentaenoic acid; $\mathrm{DHA}=$ docosahexaenoic acid; $\mathrm{PV}=$ peroxide value . 


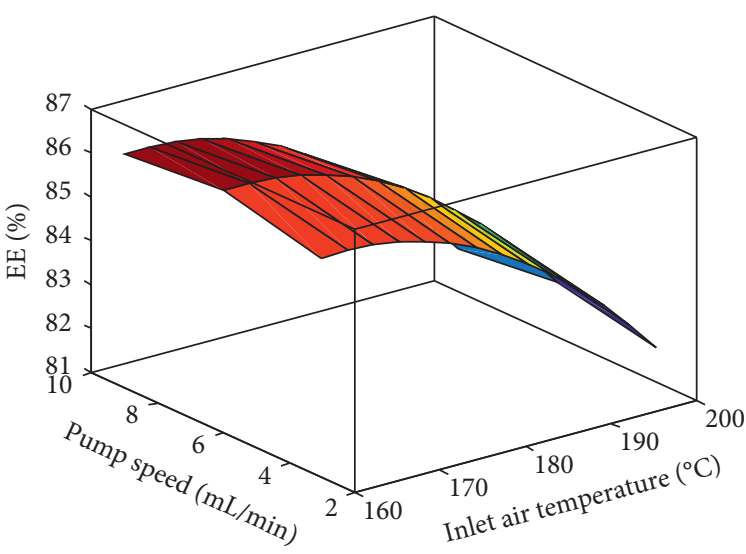

(a)

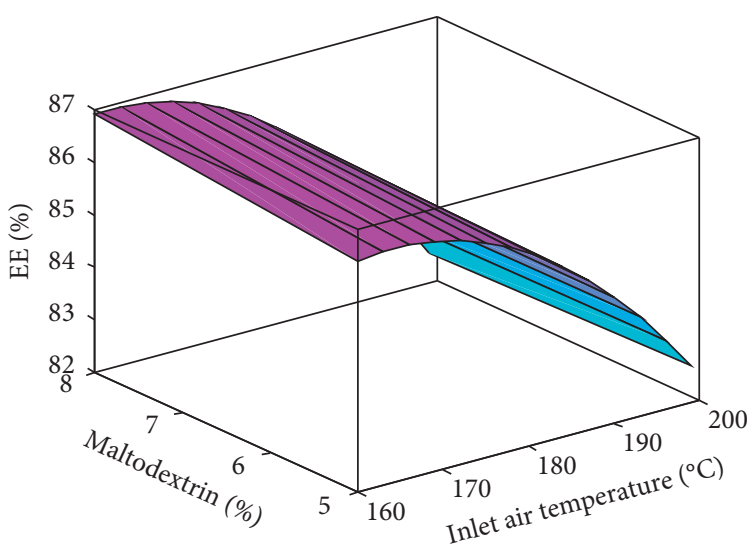

(c)

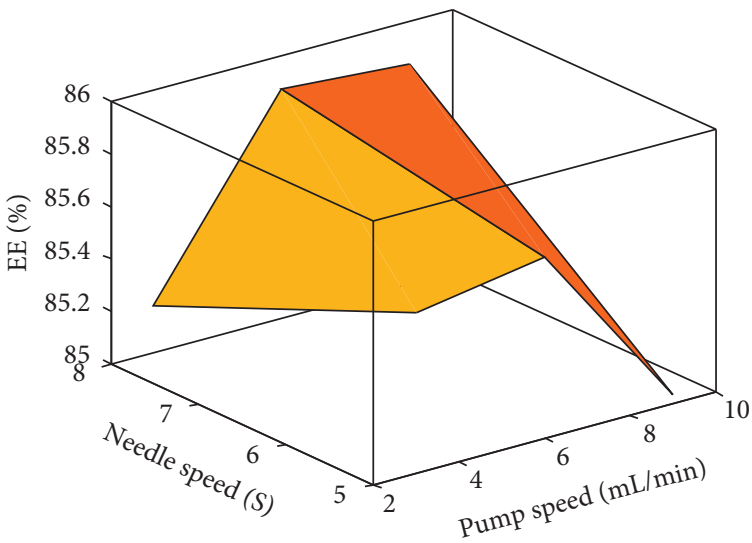

(e)

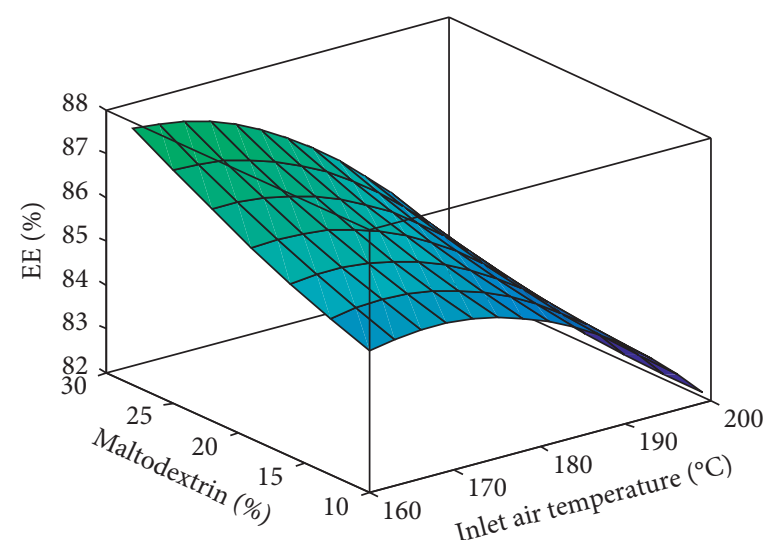

(b)

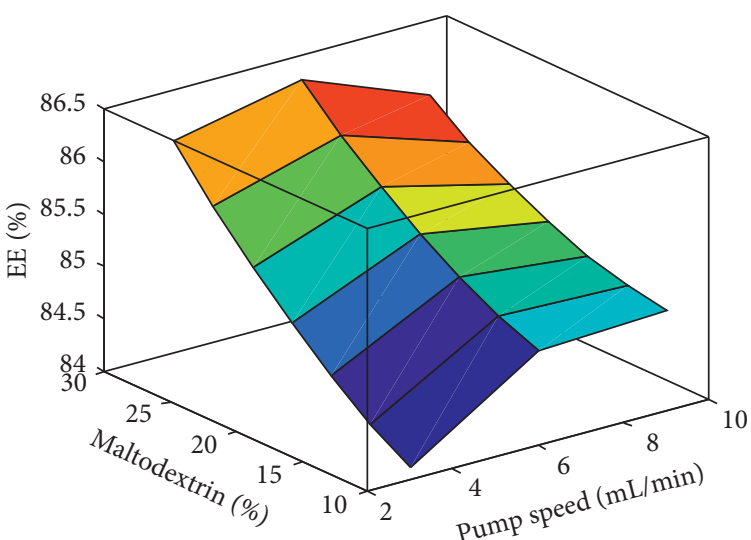

(d)

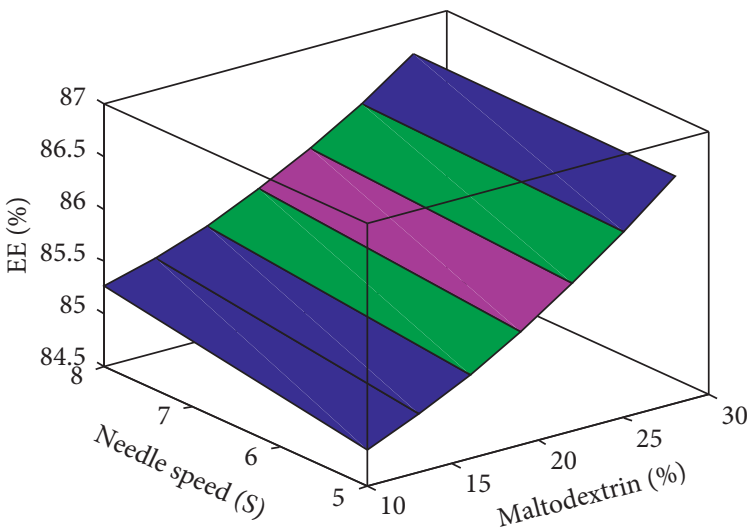

(f)

FIgURE 2: The interaction impact of spray drying parameters on encapsulation efficiency.

increases the speed of oxidation process. The findings of the present study related to PV and temperature relationship are much closer to Lavanya et al.'s [63] study in which they spray-dried the FO at IAT in the range of $100-160^{\circ} \mathrm{C}$ and PVs of SDP samples were within the range of 1.9 to $3.8 \mathrm{meqO}_{2} /$ $\mathrm{kg}$. The temperature was significantly responsible for these changes. In another work, PV of pure FO was $1.05 \mathrm{meqO}_{2} / \mathrm{kg}$ before SD and after SD process, and it was observed as $2.10-4.06 \mathrm{meqO}_{2} / \mathrm{kg}$. Higher IAT range in SD process was considered responsible for increase of oxidation level [67]. $\mathrm{Li}$ et al. [68] also observed the formation of aldehydes and ketones in milk powder at production day and during storage period. These short chain volatile compounds gradually increased at high operating IAT conditions and ultimately cause off-flavors and off-odors. The PV of powdered milk produced by SD ranged from 0.143 to $0.367 \mathrm{meqO}_{2} / \mathrm{kg}$ [68]. Santhanam et al. [41] observed the variation in the PV of dried SO preparation, which was maybe due to the oxidative reactions and uncontrolled factors like oxygen, light, and heat. The formation of pores 


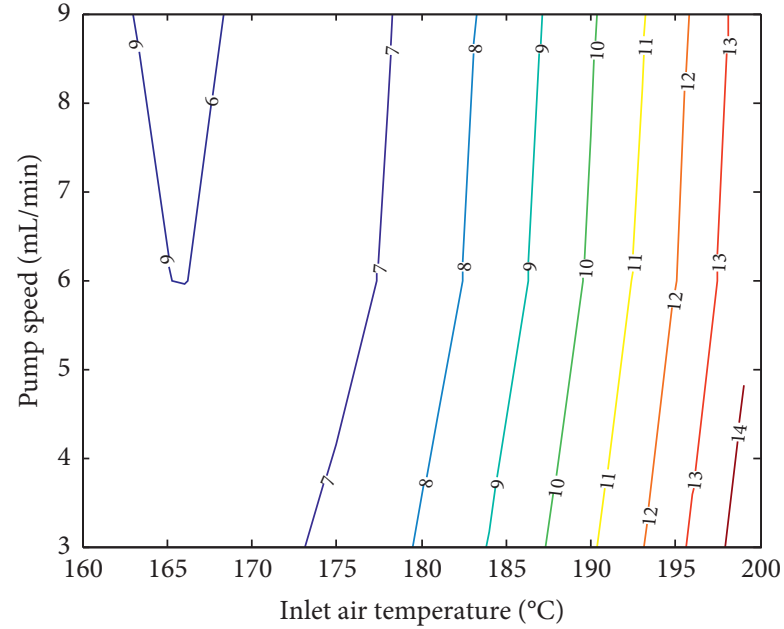

(a)

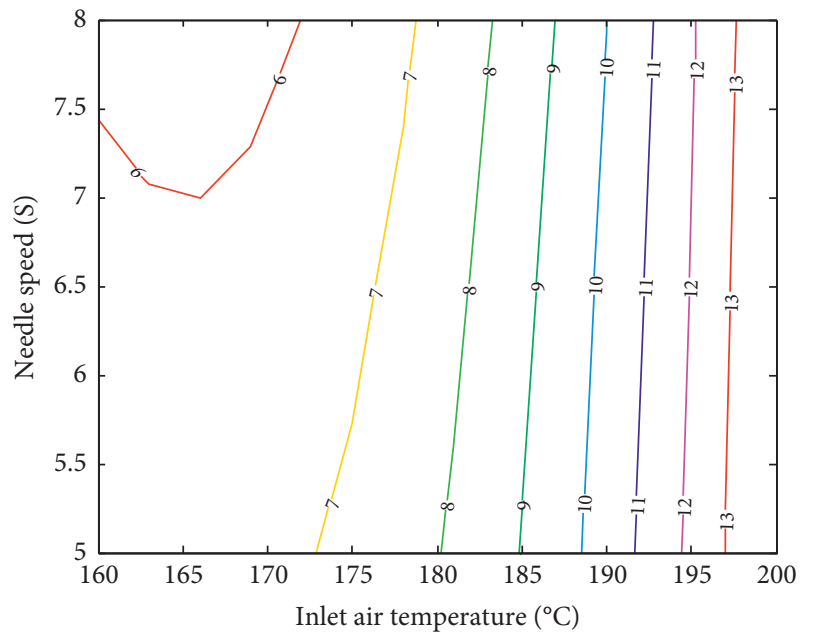

(c)

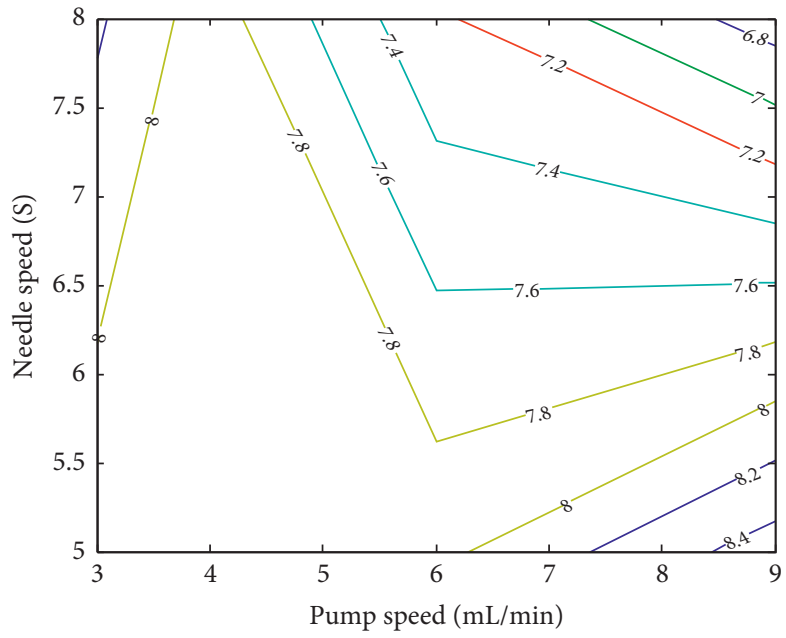

(e)

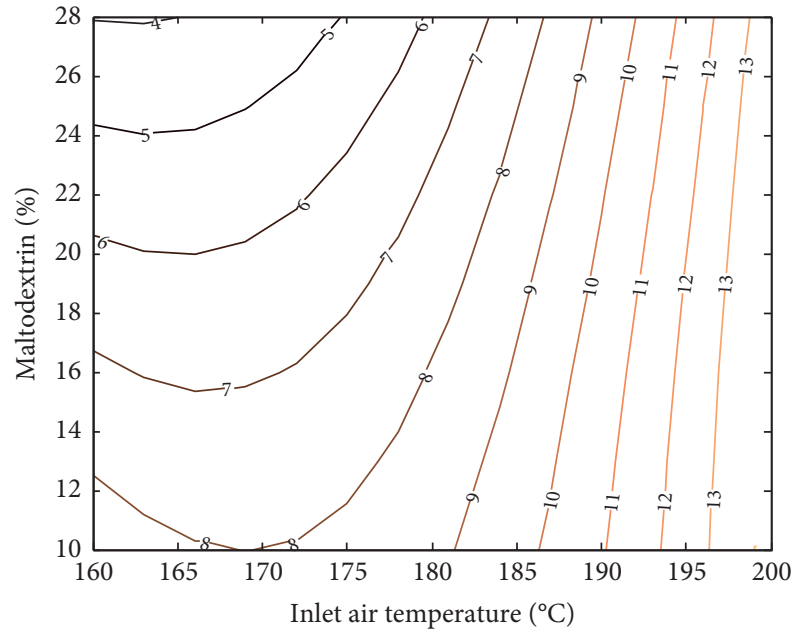

(b)

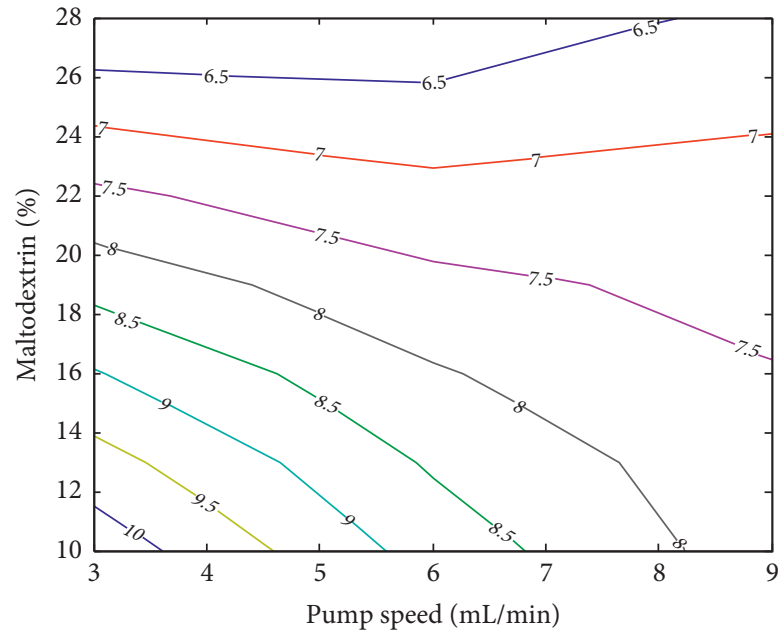

(d)

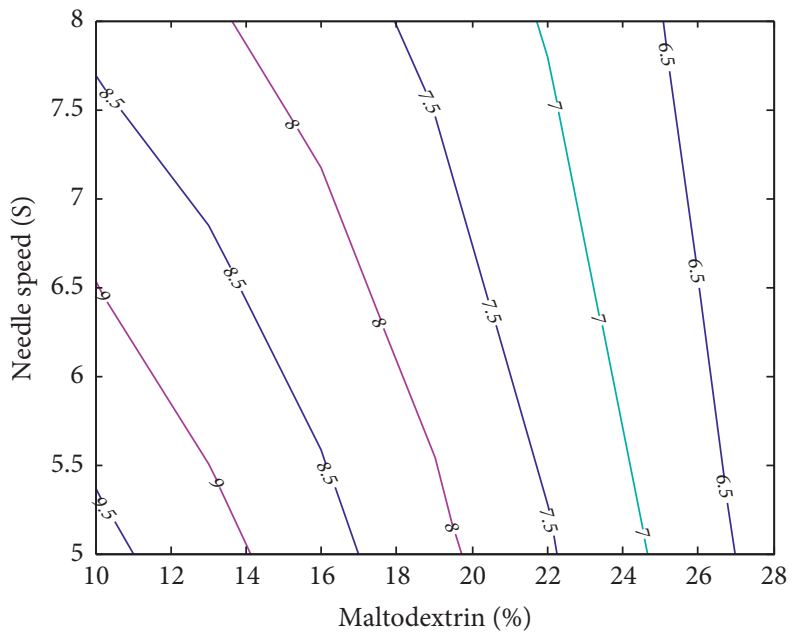

(f)

FIGURE 3: The mutual interaction impact of spray drying conditions on percent EPA loss. 


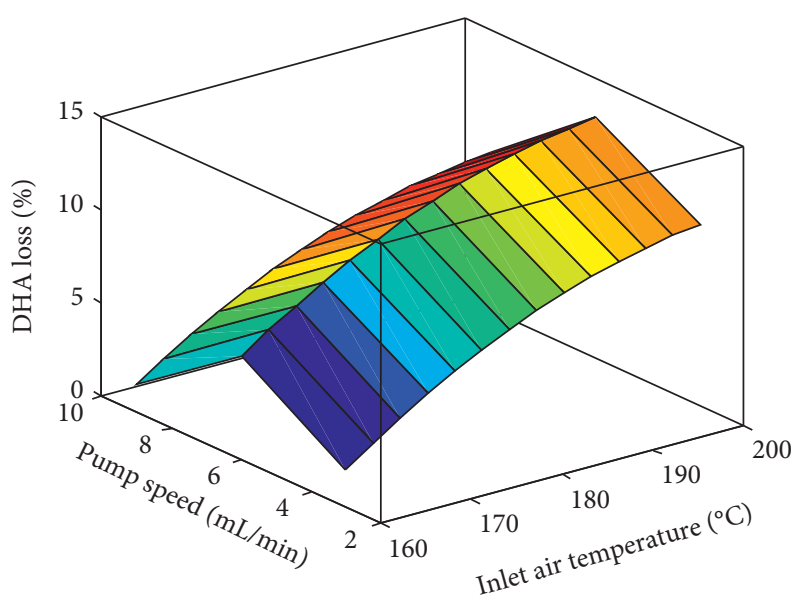

(a)

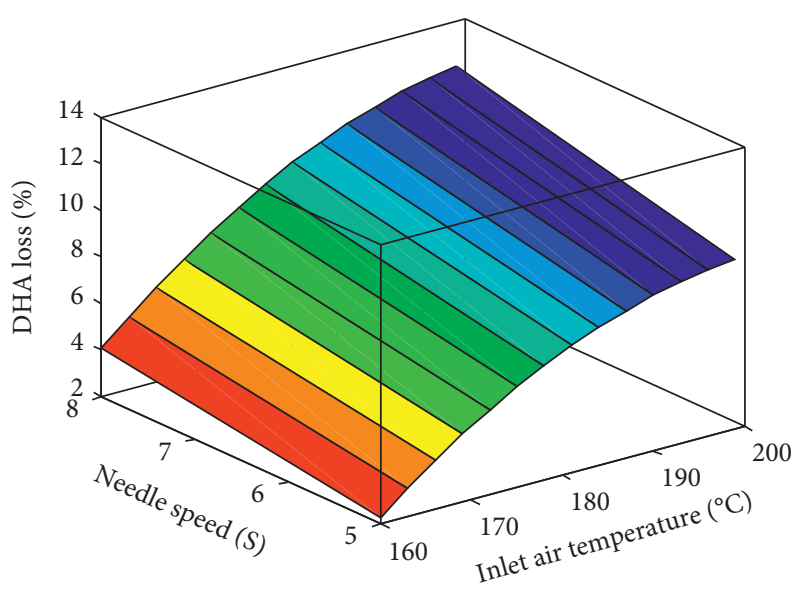

(c)

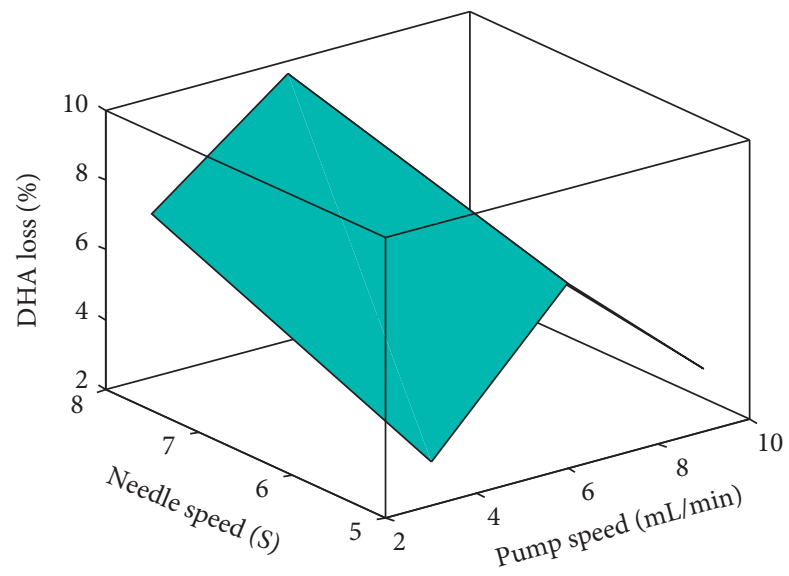

(e)

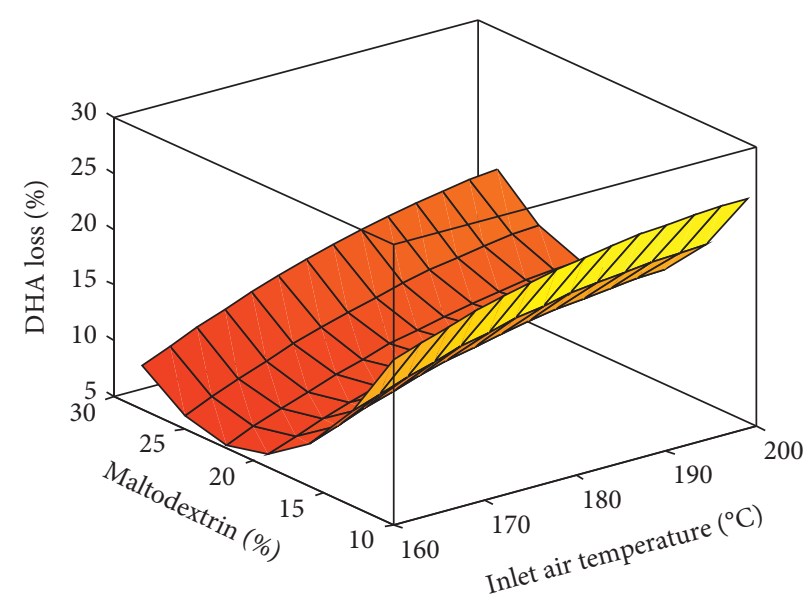

(b)

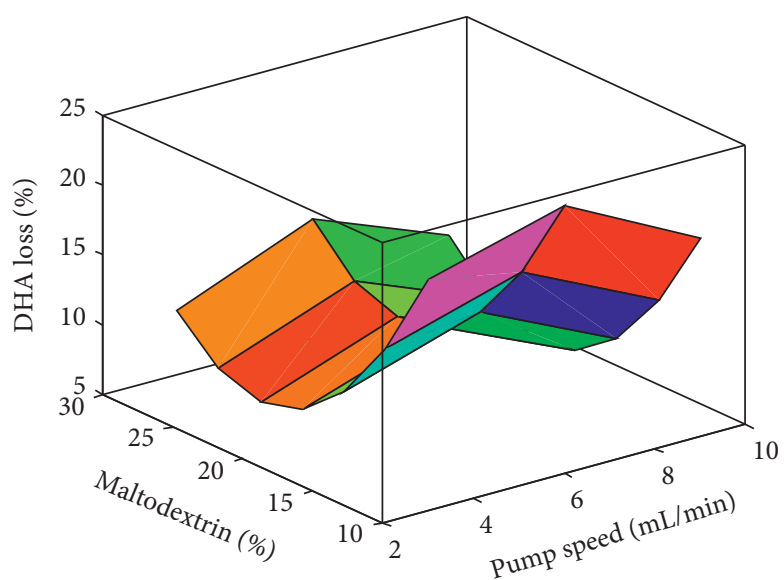

(d)

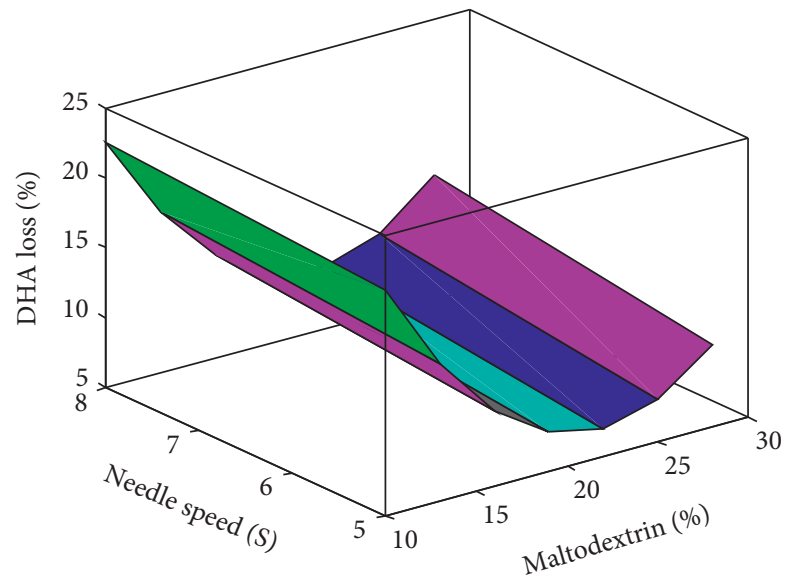

(f)

FIGURE 4: The interaction impact of spray drying independent parameters on percent DHA loss.

on surface of SDP supported the oxygen movement and enhanced the oxidation as noted from elevated PVs. Autooxidation of SDP occurs due to changes in independent variable factors [69]. The PS and IAT relationship was noted to be a significant factor to increase or decrease the PV of the SDP samples. It is noteworthy to mention that the higher temperature profile during SD process causes crust cracks, while reduced PS leads to overcooking. Meanwhile, lower NS produced particles with bigger size which is maybe due to more available time for crust formation [70]. PS should be adjusted to avoid too much liquid spray during process. The high rate of PS can cause agglomeration, which may lower powder functional properties [71]. The quick crust formation of SDP leads to the high EE rate and this would 


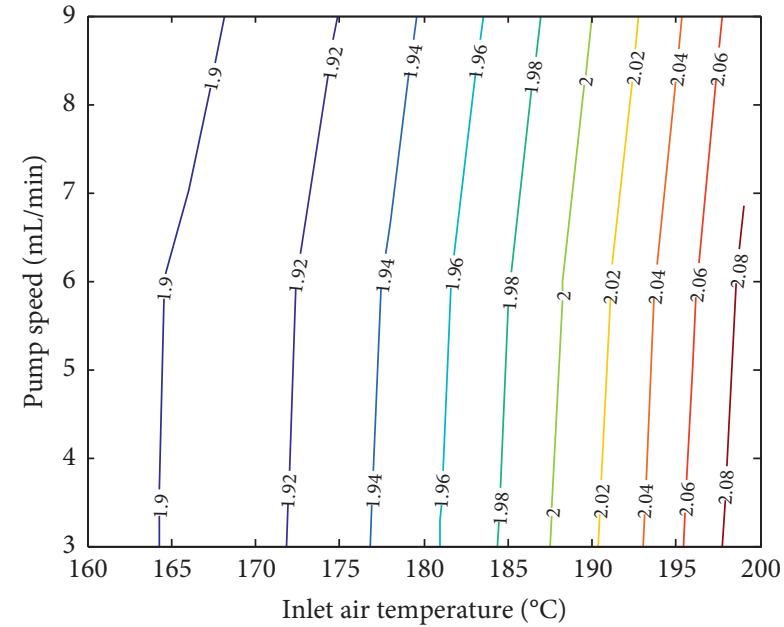

(a)

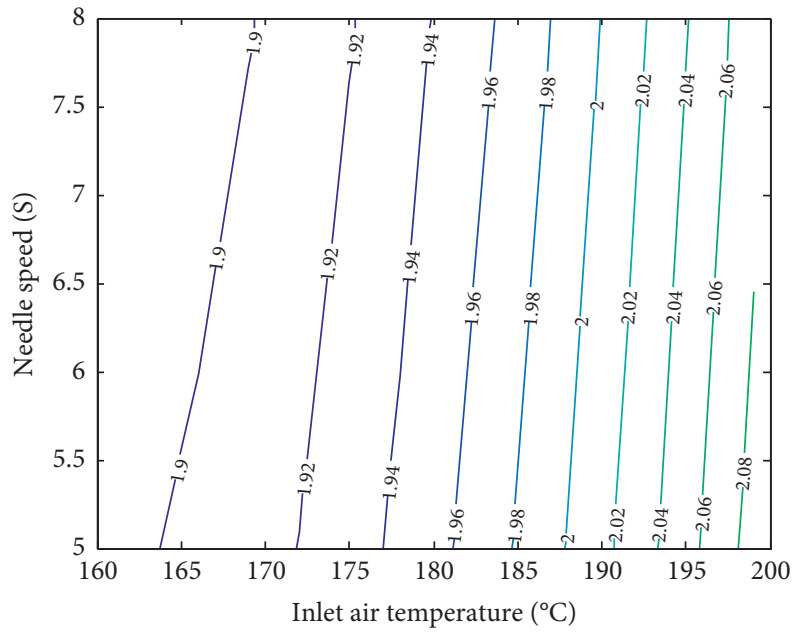

(c)

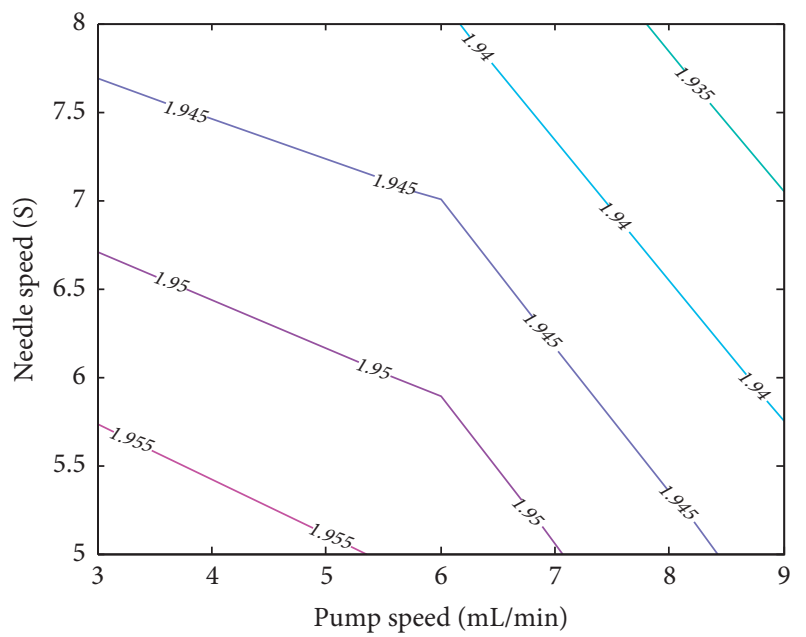

(e)

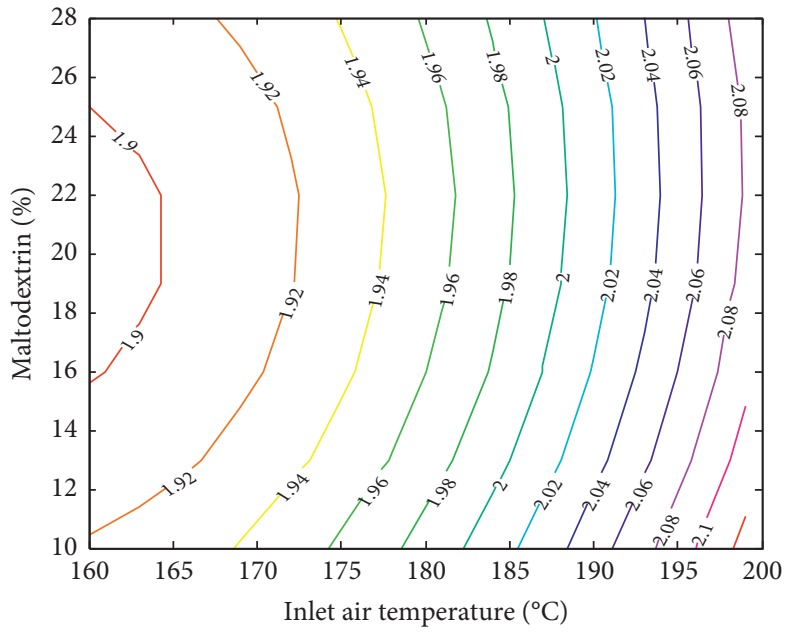

(b)

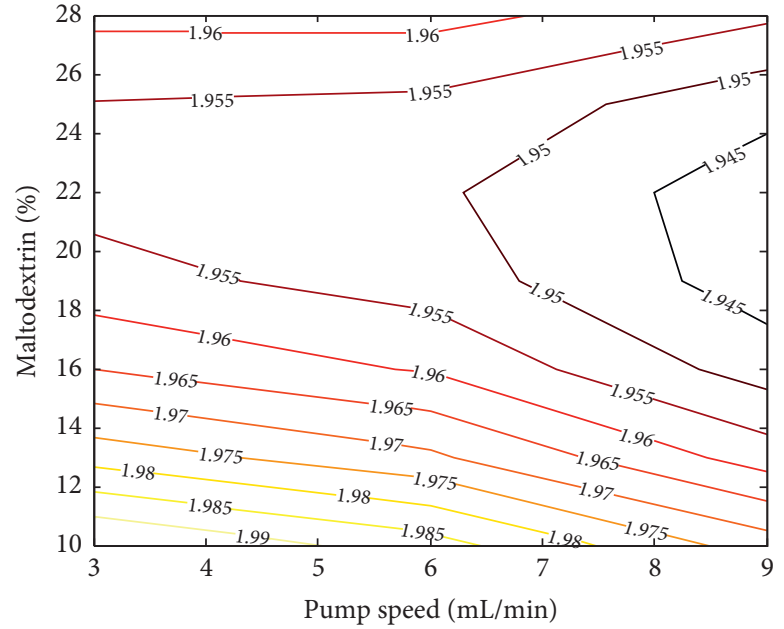

(d)

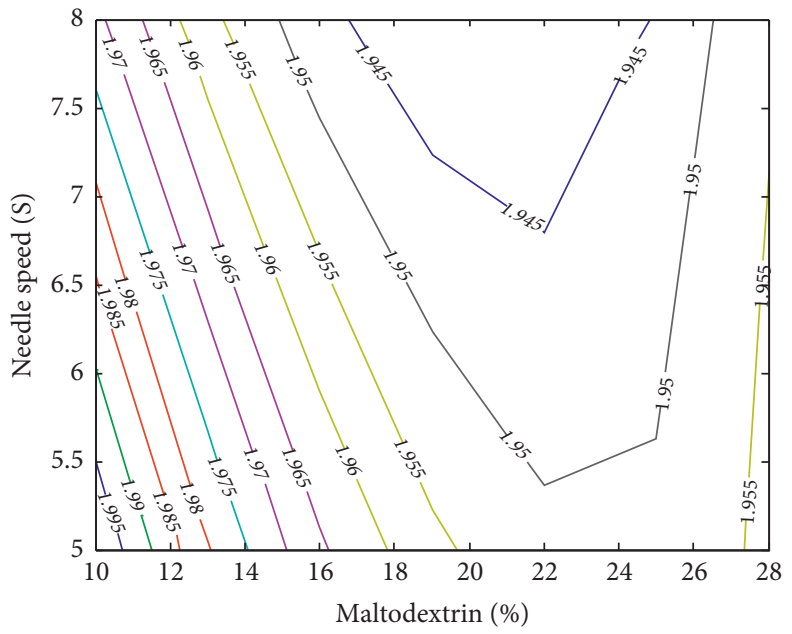

(f)

FIgURE 5: The mutual interaction impact of spray drying conditions on peroxide value of spray dried powder samples. 
definitely protect the core from oxidation [58]. Tonon et al. [72] also reported that the high IAT enhanced the PV. Overall, SD is a best-suited process for protection of oil content inside the WM without significant undesirable quality changes.

\section{Conclusions}

Results obtained during this study indicate that the fish oil can be used to deliver the omega-3 fatty acids in a food system like milk. Moreover, the spray drying technology can be employed to stabilize the EPA- and DHA-enriched fish oil and milk blends. However, the operating variables influenced the performance of spray drying process. The spray drying temperature was noted to be a key parameter for omega-3 fatty acids retention and affecting the oxidative stability of spray dried powder samples. Furthermore, more research would be needed regarding the sensory acceptability to understand the discerning consumers liking and disliking about spray dried products. In future studies, the long-term storage stability of fish oil supplemented spray dried products should also be investigated by using different oxidation indicators.

\section{Data Availability}

The data used to support the conclusions of this article are included within the article.

\section{Conflicts of Interest}

The authors declare that they have no conflicts of interest.

\section{Acknowledgments}

The authors are highly obliged to the Library Department, Government College University Faisalabad (GCUF), and IT Department, Higher Education Commission (HEC, Islamabad), for access to journals, books, and valuable database. The research was completed after utilizing the available resources in the Department and University. The spray dryer equipment as well as chemical and glassware support was obtained from HEC Pakistan Funded Project (7738/Punjab/ NRPU/R\&D/HEC/2017).

\section{References}

[1] P. Kaushik, K. Dowling, C. J. Barrow, and B. Adhikari, "Microencapsulation of omega-3 fatty acids: a review of microencapsulation and characterization methods," Journal of Functional Foods, vol. 19, pp. 868-881, 2015.

[2] T. Ishihara, M. Yoshida, and M. Arita, "Omega-3 fatty acidderived mediators that control inflammation and tissue homeostasis," International Immunology, vol. 31, no. 9, pp. 559-567, 2019.

[3] A. L. Fadini, I. D. Alvim, I. P. Ribeiro et al., "Innovative strategy based on combined microencapsulation technologies for food application and the influence of wall material composition," LWT, vol. 91, pp. 345-352, 2018.

[4] B. P. Mohanty, S. Ganguly, A. Mahanty et al., "DHA and EPA content and fatty acid profile of 39 food fishes from India,"
BioMed Research International, vol. 2016, Article ID 4027437, 14 pages, 2016.

[5] A. J. Richardson, "Clinical trials of fatty acid treatment in ADHD, dyslexia, dyspraxia and the autistic spectrum," Prostaglandins, Leukotrienes and Essential Fatty Acids, vol. 70, no. 4, pp. 383-390, 2004.

[6] M. P. Freeman, J. R. Hibbeln, K. L. Wisner et al., "Omega-3 fatty acids: evidence basis for treatment and future research in psychiatry," Journal of Clinical Psychiatry, vol. 67, no. 12, pp. 1954-1967, 2006.

[7] P. M. Kris-Etherton, J. A. Grieger, and T. D. Etherton, "Dietary reference intakes for DHA and EPA," Prostaglandins, Leukotrienes and Essential Fatty Acids, vol. 81, no. 2-3, pp. 99-104, 2009.

[8] K. F. Michaelsen, K. G. Dewey, A. B. Perez-Exposito, M. Nurhasan, L. Lauritzen, and N. Roos, "Food sources and intake of n-6 and n-3 fatty acids in low-income countries with emphasis on infants, young children (6-24 months), and pregnant and lactating women," Maternal \& Child Nutrition, vol. 7, no. 2, pp. 124-140, 2011.

[9] E. N. Smit, E. A. Oelen, E. Seerat, F. A. Muskiet, and E. R. Boersma, "Breast milk docosahexaenoic acid (DHA) correlates with DHA status of malnourished infants," Archives of Disease in Childhood, vol. 82, no. 6, pp. 493-494, 2000.

[10] H. A. Hamilton, R. Newton, N. A. Auchterlonie, and D. B. Müller, "Systems approach to quantify the global omega3 fatty acid cycle," Nature Food, vol. 1, no. 1, pp. 59-62, 2020.

[11] R. Micha, S. Khatibzadeh, P. Shi et al., "Global, regional, and national consumption levels of dietary fats and oils in 1990 and 2010: a systematic analysis including 266 country-specific nutrition surveys," BMJ, vol. 348, no. 18, Article ID g2272, 2014.

[12] World Health Organization, Diet, Nutrition, and The Prevention of Chronic Diseases Report of A Joint WHO/FAO Expert Consultation, World Health Organization, Geneva, Switzerland, 2003.

[13] A. C. Patterson, R. C. Hogg, D. M. Kishi, and K. D. Stark, "Biomarker and dietary validation of a Canadian food frequency questionnaire to measure eicosapentaenoic and docosahexaenoic acid intakes from whole food, functional food, and nutraceutical sources," Journal of the Academy of Nutrition and Dietetics, vol. 112, no. 7, pp. 1005-1014, 2012.

[14] M. Nickerson, C. Yan, S. Cloutier, and W. Zhang, "Protection and masking of omega-3 and -6 oils via microencapsulation," Microencapsulation in the Food Industry, vol. 32, pp. 485-500, 2014.

[15] M. Niva, "All foods affect health: understandings of functional foods and healthy eating among health-oriented Finns," Appetite, vol. 48, no. 3, pp. 384-393, 2007.

[16] C. Molinari, P. Risé, C. Guerra et al., "Eight-week consumption of milk enriched with omega 3 fatty acids raises their blood concentrations yet does not affect lipids and cardiovascular disease risk factors in adult healthy volunteers," PharmaNutrition, vol. 2, no. 4, pp. 141-148, 2014.

[17] F. Visioli and A. Strata, "Milk, dairy products, and their functional effects in humans: a narrative review of recent evidence," Advances in Nutrition, vol. 5, no. 2, pp. 131-143, 2014.

[18] F. Visioli, P. Risè, E. Plasmati, F. Pazzucconi, C. R. Sirtori, and C. Galli, "Very low intakes of n-3 fatty acids incorporated into bovine milk reduce plasma triacylglycerol and increase HDLcholesterol concentrations in healthy subjects," Pharmacological Research, vol. 41, no. 5, pp. 571-576, 2000.

[19] N. Upadhyay, A. Goyal, A. Kumar, D. L. Ghai, and R. Singh, "Preservation of milk and milk products for analytical 
purposes," Food Reviews International, vol. 30, no. 3, pp. 203-224, 2014.

[20] E. Lopez-Huertas, "Health effects of oleic acid and long chain omega-3 fatty acids (EPA and DHA) enriched milks. A review of intervention studies," Pharmacological Research, vol. 61, no. 3, pp. 200-207, 2010.

[21] R. A. Harrison, M. Sagara, A. Rajpura et al., "Can foods with added soya-protein or fish-oil reduce risk factors for coronary disease? A factorial randomised controlled trial," Nutrition, Metabolism and Cardiovascular Diseases, vol. 14, no. 6, pp. 344-350, 2004.

[22] E. Arab-Tehrany, M. Jacquot, C. Gaiani, M. Imran, S. Desobry, and M. Linder, "Beneficial effects and oxidative stability of omega-3 long-chain polyunsaturated fatty acids," Trends in Food Science \& Technology, vol. 25, no. 1, pp. 24-33, 2012.

[23] M. K. Keogh, B. T. O'kennedy, J. Kelly et al., "Stability to oxidation of spray-dried fish oil powder microencapsulated using milk ingredients," Journal of Food Science, vol. 66, no. 2, pp. 217-224, 2001.

[24] A. Khan, M. T. Munir, W. Yu, and B. R. Young, "Near infrared spectroscopy and data analysis for predicting milk powder quality attributes," International Journal of Dairy Technology, vol. 74, no. 1, pp. 235-245, 2020.

[25] G. Chegini and M. Taheri, "Whey powder: process technology and physical properties: a review," Middle-East Journal of Scientific Research, vol. 13, no. 10, pp. 1377-1387, 2013.

[26] N. Burke, K. A. Zacharski, M. Southern, P. Hogan, M. P. Ryan, and C. C. Adley, "The dairy industry: process, monitoring, standards, and quality," Descriptive Food Science, vol. 25, 2018.

[27] L. Haldar and D. N. Gandhi, "Development of vacuum-dried probiotic milk powder with Bacillus coagulans," International Journal of Dairy Technology, vol. 73, no. 1, pp. 283-291, 2020.

[28] A. Gambro, "Projective Techniques to study consumer perception of food," Current Opinion in Food Science, vol. 21, pp. 46-50, 2018.

[29] A. H. De Oliveira, M. E. R. C. Mata, M. Fortes, M. E. M. Duarte, M. Pasquali, and H. M. Lisboa, "Influence of spray drying conditions on the properties of whole goat milk," Drying Technology, vol. 10, pp. 1-12, 2020.

[30] S. S. C. Novaes, F. B. H. Dantas, I. D. Alvim, A. M. R. de Oliveira Miguel, S. T. Dantas, and R. M. V. Alves, "Stability of omega-3 enriched milk powder in different commercial packages stored under accelerated conditions of temperature and relative humidity," International Dairy Journal, vol. 88, pp. 1-9, 2019.

[31] F. C. Prado, J. L. Parada, A. Pandey, and C. R. Soccol, "Trends in non-dairy probiotic beverages," Food Research International, vol. 41, no. 2, pp. 111-123, 2008.

[32] Y. Kitamura, H. Itoh, and H. Echizen, "Experimental vacuum spray drying of probiotic foods, included with lactic acid bacteria," Journal of Food Processing and Preservation, vol. 3, no. 9, pp. 714-726, 2009.

[33] L. M. Rodríguez-Alcalá, M. V. Calvo, J. Fontecha, and L. Alonso, "Alterations in the fatty acid composition in infant formulas and $\omega 3$-PUFA enriched UHT milk during storage," Foods, vol. 8, no. 5, p. 163, 2019.

[34] A. Zouari, I. Mtibaa, M. Triki et al., "Effect of spray-drying parameters on the solubility and the bulk density of camel milk powder: a response surface methodology approach," International Journal of Dairy Technology, vol. 73, no. 3, pp. 616-624, 2013.

[35] S. Feng, A. L. Lock, and P. C. Garnsworthy, "Technical note: a rapid lipid separation method for determining fatty acid composition of milk," Journal of Dairy Science, vol. 87, no. 11, pp. 3785-3788, 2004.

[36] W. W. Christie, "A simple procedure for rapid transmethylation of glycerolipids and cholesteryl esters," Journal of Lipid Research, vol. 23, no. 7, pp. 1072-1075, 1982.

[37] L. Fang, W. Chao, Y. Ju, Y. Guo, and X. HuiJun, "Progress of determination methods for acid and peroxide values of oils and fats," Journal of Food Safety and Quality, vol. 10, no. 14, pp. 4478-4482, 2019.

[38] D. Xie, J. Jin, J. Sun et al., "Comparison of solvents for extraction of krill oil from krill meal: lipid yield, phospholipids content, fatty acids composition and minor components," Food Chemistry, vol. 233, pp. 434-441, 2017.

[39] E. Anandganesh, A. R. Nazar, G. Marichamy, Sunithadas, K. Gowtham, and S. Shanker, "Extraction, purification, composition and quality deterioration of fish body oil extracted from Sardinella Fimbriata by traditional method," International Journal of Innovative Research in Medical Science, vol. 1, no. 7, pp. 2455-8737, 2016.

[40] A. Jeyakumari, G. Kothari, and G. Venkateshwarlu, "Microencapsulation of fish oil-milk based emulsion by spray drying, Impact on Oxidative Stability," Fishery Technology, vol. 51, no. 1, pp. 31-37, 2014.

[41] A. K. Santhanam, M. Lekshmi, M. K. Chouksey, G. Tripathi, and V. Gudipati, "Delivery of omega-3 fatty acids into cake through emulsification of fish oil-in-milk and encapsulation by spray drying with added polymers," Drying Technology, vol. 33, no. 1, pp. 83-91, 2015.

[42] H. C. F. Carneiro, R. V. Tonon, C. R. F. Grosso, and M. D. Hubinger, "Encapsulation efficiency and oxidative stability of flaxseed oil microencapsulated by spray drying using different combinations of wall materials," Journal of Food Engineering, vol. 115, no. 4, pp. 443-451, 2013.

[43] D. C. Montgomery, "Response surface methods and designs," in Design and Analysis of ExperimentsWiley, Hoboken, NJ, USA, 2017.

[44] I. T. Khan, M. Nadeem, M. Imran et al., "Triglyceride, fatty acid profile and antioxidant characteristics of low melting point fractions of Buffalo Milk fat," Lipids in Health and Disease, vol. 18, no. 1, p. 59, 2019.

[45] S. Stergiadis, N. P. Nørskov, S. Purup, I. Givens, and M. R. F. Lee, "Comparative nutrient profiling of retail goat and cow milk," Nutrients, vol. 11, no. 10, p. 2282, 2019.

[46] B. H. Schwendel, T. J. Wester, P. C. H. Morel et al., "Invited review: organic and conventionally produced milk-An evaluation of factors influencing milk composition," Journal of Dairy Science, vol. 98, no. 2, pp. 721-746, 2015.

[47] M. Ajmal, M. Nadeem, M. Imran, and M. Junaid, "Lipid compositional changes and oxidation status of ultra-high temperature treated Milk," Lipids in Health and Disease, vol. 17 , no. 1, p. 227, 2018.

[48] T. Ghorbanzade, S. M. Jafari, S. Akhavan, and R. Hadavi, "Nano-encapsulation of fish oil in nano-liposomes and its application in fortification of yogurt," Food Chemistry, vol. 216, pp. 146-152, 2017.

[49] O. C. Almeida, M. V. C. Ferraz, I. Susin et al., "Plasma and milk fatty acid profiles in goats fed diets supplemented with oils from soybean, linseed or fish," Small Ruminant Research, vol. 170, pp. 125-130, 2019.

[50] H. L. Tan and K. M. McGrath, "Na-caseinate/oil/water systems: emulsion morphology diagrams," Journal of Colloid and Interface Science, vol. 381, no. 1, pp. 48-58, 2012. 
[51] H. C. Deeth and J. Hartanto, "Chemistry of milk - role of constituents in evaporation and drying," Dairy Powders and Concentrated Products, vol. 34, pp. 1-27, 2009.

[52] M. Guo and G. Wang, "Milk protein polymer and its application in environmentally safe adhesives," Polymers, vol. 8, no. 324, pp. 1-12, 2016.

[53] H. Habtegebriel, M. Wawire, and D. Sila, "The effect of pretreatment (Spray Drying) on the yield and selected nutritional components of whole camel milk powder," Journal of Food Science, vol. 83, no. 12, pp. 2983-2991, 2018.

[54] R. H. Myers, D. C. Montgomery, G. G. Vining, C. M. Borror, and S. M. Kowalski, "Response surface methodology: a retrospective and literature survey," Journal of Quality Technology, vol. 36, no. 1, pp. 53-77, 2004.

[55] S. V. Jangam, "An overview of recent developments and some R\&D challenges related to drying of foods," Drying Technology, vol. 29, no. 12, pp. 1343-1357, 2011.

[56] R. Bellinghausen, "Spray drying from yesterday to tomorrow: an industrial perspective," Drying Technology, vol. 37, no. 5, pp. 612-622, 2019.

[57] S. Prasertmanakit, N. Praphairaksit, W. Chiangthong, and N. Muangsin, "Ethyl cellulose microcapsules for protecting and controlled release of folic acid," Aaps Pharmscitech, vol. 10, no. 4, pp. 1104-1112, 2009.

[58] M. Aghbashlo, H. Mobli, A. Madadlou, and S. Rafiee, "Influence of wall material and inlet drying air temperature on the microencapsulation of fish oil by spray drying," Food and Bioprocess Technology, vol. 6, no. 6, pp. 1561-1569, 2013.

[59] Y. Wu, L. Zou, J. Mao, J. Huang, and S. Liu, "Stability and encapsulation efficiency of sulforaphane microencapsulated by spray drying," Carbohydrate Polymers, vol. 102, pp. 497503, 2014

[60] D. Alvarenga Botrel, S. Vilela Borges, R. Victória de Barros Fernandes, A. Dantas Viana, J. Maria Gomes da Costa, and G. Reginaldo Marques, "Evaluation of spray drying conditions on properties of microencapsulated oregano essential oil," International Journal of Food Science \& Technology, vol. 47, no. 11, pp. 2289-2296, 2012.

[61] T. V. Huynh, N. Caffin, G. A. Dykes, and B. Bhandari, "Optimization of the microencapsulation of lemon myrtle oil using response surface methodology," Drying Technology, vol. 26, no. 3, pp. 357-368, 2008.

[62] M. I. Amaro, L. Tajber, O. I. Corrigan, and A. M. Healy, "Optimisation of spray drying process conditions for sugar nanoporous microparticles (NPMPs) intended for inhalation," International Journal of Pharmaceutics, vol. 421, no. 1, pp. 99-109, 2011.

[63] M. N. Lavanya, T. Kathiravan, J. A. Moses, and C. Anandharamakrishnan, "Influence of spray-drying conditions on microencapsulation of fish oil and chia oil," Drying Technology, vol. 38, no. 3, pp. 279-292, 2020.

[64] C. Encina, C. Vergara, B. Giménez, F. Oyarzún-Ampuero, and P. Robert, "Conventional spray-drying and future trends for the microencapsulation of fish oil," Trends in Food Science \& Technology, vol. 56, pp. 46-60, 2016.

[65] R. Wang, Z. Tian, and L. Chen, "A novel process for microencapsulation of fish oil with barley protein," Food Research International, vol. 44, no. 9, pp. 2735-2741, 2011.

[66] Y. Serfert, S. Drusch, B. Schmidt-Hansberg, M. Kind, and K. Schwarz, "Process engineering parameters and type of n-octenylsuccinate-derivatised starch affect oxidative stability of microencapsulated long chain polyunsaturated fatty acids," Journal of Food Engineering, vol. 95, no. 3, pp. 386-392, 2009.
[67] W. Kolanowski, M. Ziolkowski, J. Weißbrodt, B. Kunz, and G. Laufenberg, "Microencapsulation of fish oil by spray drying--impact on oxidative stability Part 1," European Food Research and Technology, vol. 222, no. 3-4, pp. 336-342, 2006.

[68] Y. Li, L. Zhang, and W. Wang, "Formation of aldehyde and ketone compounds during production and storage of milk powder," Molecules, vol. 17, no. 8, pp. 9900-9911, 2012.

[69] S. Drusch and S. Berg, "Extractable oil in microcapsules prepared by spray-drying: localisation, determination and impact on oxidative stability," Food Chemistry, vol. 109, no. 1, pp. 17-24, 2008.

[70] G. A. Reineccius, “The spray drying of food flavors,” Drying Technology, vol. 22, no. 6, pp. 1289-1324, 2004.

[71] S. Chever, S. Méjean, A. Dolivet et al., "Agglomeration during spray drying: physical and rehydration properties of whole milk/sugar mixture powders," LWT - Food Science and Technology, vol. 83, pp. 33-41, 2017.

[72] R. V. Tonon, C. R. F. Grosso, and M. D. Hubinger, "Influence of emulsion composition and inlet air temperature on the microencapsulation of flaxseed oil by spray drying," Food Research International, vol. 44, no. 1, pp. 282-289, 2011. 